Review Article

\title{
Using Sibling Designs to Understand Neurodevelopmental Disorders: From Genes and Environments to Prevention Programming
}

\author{
Mark Wade, ${ }^{1}$ Heather Prime, ${ }^{1}$ and Sheri Madigan ${ }^{2}$ \\ ${ }^{1}$ Department of Applied Psychology and Human Development, University of Toronto, 252 Bloor Street W., \\ Toronto, ON, Canada M5S 1V6 \\ ${ }^{2}$ Department of Psychology, University of Calgary, 2500 University Drive NW, Calgary, AB, Canada T2N 1N4
}

Correspondence should be addressed to Mark Wade; wadem2@gmail.com

Received 12 March 2015; Revised 5 June 2015; Accepted 28 June 2015

Academic Editor: Ping I. Lin

Copyright (C) 2015 Mark Wade et al. This is an open access article distributed under the Creative Commons Attribution License, which permits unrestricted use, distribution, and reproduction in any medium, provided the original work is properly cited.

\begin{abstract}
Neurodevelopmental disorders represent a broad class of childhood neurological conditions that have a significant bearing on the wellbeing of children, families, and communities. In this review, we draw on evidence from two common and widely studied neurodevelopmental disorders-autism spectrum disorder (ASD) and attention-deficit hyperactivity disorder (ADHD)— to demonstrate the utility of genetically informed sibling designs in uncovering the nature and pathogenesis of these conditions. Specifically, we examine how twin, recurrence risk, and infant prospective tracking studies have contributed to our understanding of genetic and environmental liabilities towards neurodevelopmental morbidity through their impact on neurocognitive processes and structural/functional neuroanatomy. It is suggested that the siblings of children with ASD and ADHD are at risk not only of clinically elevated problems in these areas, but also of subthreshold symptoms and/or subtle impairments in various neurocognitive skills and other domains of psychosocial health. Finally, we close with a discussion on the practical relevance of sibling designs and how these might be used in the service of early screening, prevention, and intervention efforts that aim to alleviate the negative downstream consequences associated with disorders of neurodevelopment.
\end{abstract}

\section{Neurodevelopmental Disorders: Overview and Frame}

Neurodevelopmental disorders are brain-based disorders of growth and development that have a significant impact on children's mental, emotional, and psychosocial health. Among the most common and widely studied neurodevelopmental disorders are autism spectrum disorder (ASD) and attention-deficit hyperactivity disorder (ADHD $[1,2])$. The etiology of these conditions has yet to be completely mapped; however, there is strong evidence for a role of both genetic and environmental influences operating together in their pathogenesis [3-7]. As human brain development is shaped by continuous interactions between genetic and environmental factors, neurocognitive functioning may be considered an intermediate phenotype linking genes (and environments) to symptom manifestations of disorders [8]. A major problem faced by developmental scientists and clinicians is that, after symptoms have emerged and a diagnosis has been made, it is difficult to disentangle the relative (and joint) contribution of these factors. The fallout is a propensity to intervene with remedial programs that target symptoms rather than the factors and processes that predispose to disordered phenotypes. Although this is a reasonable and necessary endeavour, there are significant social and economic costs associated with the management of these conditions, related to lost productivity, medical care, and special education services [9-14]. In addition, children with either ASD or ADHD experience more social, familial, academic, and occupational difficulties [15, 16], suggesting tremendous personal burden as a result of persistent problems across the lifespan.

Given the individual, familial, and societal burden associated with neurodevelopmental disorders, there is a crucial need for methods of early detection to enable prevention 
programming prior to the emergence of fully fledged symptoms $[17,18]$. The goal of this review is to discuss how genetically sensitive sibling designs offer one such method for understanding the basis and risk of ASD and ADHD, as well as their overlap, and to highlight the utility of these designs in crafting prevention and intervention programs that may help ameliorate the negative downstream sequelae of neurodevelopmental morbidity. Here, we operationalize sibling design as any genetically informed design that capitalizes on a comparison or evaluation of traits in genetically similar individuals, including monozygotic or dizygotic twins, nontwin full siblings, or half-siblings.

\section{Autism Spectrum Disorder (ASD)}

2.1. Overview of ASD. The prevalence of ASD is estimated at around $1 \%$ of the population [19-21], with representation across all racial, ethnic, and socioeconomic groups. Notably, the prevalence of ASD has increased over the last 15 years $[20,22]$. This increase has almost certainly been shaped by a broadening of diagnostic criteria as well as increased awareness and improved early detection of ASD [23]. Whether there is also a genuine secular increase in ASD is currently not clear from the extant literature [24]. The previous version of the Diagnostic and Statistical Manual (DSM-IV) characterized autism by a triad of problems, including impaired social interaction, social communication, and restricted/repetitive patterns of behaviour, interest, or activities. The new version of this manual (DSM-5) only demarcates two clusters, with social communication and interaction under one umbrella and repetitive behaviours under the other. Also, DSM-5 introduced Social Communication Disorder, for which there is some concern that individuals previously meeting criteria for Asperger's Disorder or Pervasive Developmental DisorderNot Otherwise Specified (PDD-NOS) could be inadvertently classified [25]. Although this review will not elaborate on this point further, an important caveat is that most studies reported herein were conducted using DSM-IV guidelines. Where possible, we incorporate the most up-to-date literature using DSM-5 criteria.

2.2. Sibling Studies of ASD. Over the last two decades, there has been a shift towards viewing ASD symptomatology along a quantitative spectrum as opposed to representing a discrete disorder [26]. In this regard, diagnosis is ultimately the categorical distinction of highly variable quantitative cognitive and behavioural traits. This relatively new conceptualization of autism as a spectrum disorder has raised questions about its pathogenesis, which in turn has demanded the application of a variety of methodological approaches for examining its etiology. One such methodology is the sibling design, which explores the siblings of children with an ASD diagnosis in order to understand the genetic and environmental contributors to the disorder, as well as to delineate other risk and protective factors and early markers associated with ASD in high-risk children. Ultimately, the information obtained from such designs positions researchers, clinicians, and policymakers to create and implement prevention efforts that target children who are susceptible to the disorder.
2.2.1. Twin Designs of ASD. The genetic pathophysiology of ASD is supported by three primary sibling-related designs. The first, called a twin study, compares monozygotic (MZ) twins (who share $100 \%$ of their genetic information) to dizygotic (DZ) twins (who like nontwin siblings share 50\% of their genes but like MZ twins share the same intrauterine environment). In a twin study, if the concordance rate among MZ twins is higher than that among DZ twins, then genetic influences are assumed. This is because the primary differences between MZ and DZ twins, aside from nonshared factors (e.g., experiences outside the home, friends, etc.), are genetically mediated. Twin studies to date yield heritability estimates of ASD between 70 and 80\% [27-29]. Aside from one recent study suggesting a significant contribution of shared environmental factors to ASD (experiences that are common to both twins, e.g., socioeconomic status and parental mental health problems [4]), these studies have generally reported small or nonsignificant shared environmental effects. In general, these studies of twins are indicative of strong familial, or genetic, risk of developing ASD [30]. Also, twin studies have shown that ASD traits are moderately to highly heritable whether measured continuously or at extreme, clinical levels, with the overarching suggestion that ASD may best be considered along a continuum that varies genetically throughout the population $[26,29]$.

The presumed effect of genetic influences on development and behaviour is through endophenotypic variability in brain functioning and neurocognition [31]. In terms of neuroanatomy, clinically concordant MZ twins show more similarity in structural neuroanatomy than discordant MZ twins, despite the fact that discordant twins are more similar than nontwins in various brain regions $[32,33]$. This finding cannot be easily explained by differences in heritability factors, as all MZ twins share $100 \%$ of their genes. However, it is interesting to note that approximately $65-75 \%$ of $\mathrm{MZ}$ twins are monochorionic (MC)-meaning they share the same placenta-while the remaining $25-35 \%$ of $\mathrm{MZ}$ twins (and $100 \%$ of DZ twins) are dichorionic (DC), having different placentas. We know of no twin studies that have differentiated between MC-MZ and DC-MZ twins, although mathematical equations have been derived to predict this variability [34]. These mathematical models suggest that MC-MZ twins, who have virtually identical intrauterine environments in addition to genetic likeness, would have concordance rates at about 95-100\%, while DC-MZ twins would exhibit concordance rates comparable to $\mathrm{DZ}$ twins or ordinary nontwin siblings. If true, this suggests that an intrauterine trigger or insult that is more similarly shared by MC-MZ twins may generate more comparable deficits in neural functioning that underlie the social and cognitive impairments that characterize ASD. Alternatively, DC-MZ twins, who are more likely to be discordant for a diagnosis, may evince comparable neuroanatomy in some areas but not others, which explain the relatively lower symptom overlap, perhaps at subclinical levels that do not warrant full diagnosis. These purported models require explicit empirical investigation in future studies.

In sum, these studies point to a strong genetic pathophysiology of ASD, and studies that link the genes involved in ASD to discrete brain circuits that support cognitive functions will 
prove critical in advancing our knowledge of these complex and as-yet unidentified mechanisms of development [35].

2.2.2. Sibling Recurrence Rates of ASD. The second sibling approach to studying the etiology of ASD is to examine recurrence rates in nontwin sibling pairs. These methods seek to determine the likelihood of an ASD diagnosis in the younger siblings of a child with an existing ASD diagnosis. Recent studies report that when followed from infancy to early childhood, the risk of developing ASD is between 10 and $20 \%$ for siblings of children with ASD compared to about $1 \%$ for siblings of a typically developing child [36-38]. Moreover, two studies of over 5,000 nontwin sibling pairs showed that the recurrence rate of ASD in full siblings ( $\sim 10 \%)$ is about twice that of half-siblings ( $\sim 5 \%)$, providing evidence for an apparent dose-response relationship between degree of genetic relatedness and risk of ASD in nontwin siblings $[39,40]$.

Interestingly, findings from twin studies suggest that the recurrence risk in DZ twins is about 30\% [27], considerably higher than that observed in nontwin siblings. Given that a shared in utero environment is one of the foremost factors differentiating DZ from nontwin siblings, these findings again suggest that intrauterine factors, such as the elicitation of deleterious antibodies or differential recruitment of maternal resources, may represent additional sources of variability contributing to the risk of ASD. Indeed, a number of prenatal environmental agents have been linked to an increased risk of ASD, including maternal medications during pregnancy (e.g., thalidomide and valproic acid [41, 42]), maternal viral infections (e.g., cytomegalovirus [43]), and possibly prenatal exposure to organophosphates [44] and phthalates [45]. To the extent that the intrauterine environment is in fact more similar for DZ twins than for nontwin siblings, it is also possible that the increased recurrence risk of DZ twins compared to nontwin siblings reflects a shared genetic risk interacting with shared prenatal exposures [46, 47]. In sum, not only is the recurrence risk of ASD higher in siblings than nonsiblings, but also there appears to be an increasingly heightened risk as a function of genetic relatedness and the extent of environmental similarity that may manifest in distinct neural, cognitive, and socioemotional profiles that typify ASD [48].

2.2.3. Prospective Tracking of Infants at High Risk of ASD. The third stream of research utilizing sibling designs are those that prospectively track infants at risk for ASD, which is usually operationally defined as having an older sibling with ASD. By prospectively following high-risk infants, researchers can compare those that do and do not develop ASD to one another as well as to a control group (i.e., infants with typically developing siblings). They can also compare siblings of children with ASD to the siblings of typically developing children on core neuropsychological, socioemotional, and behavioural traits to identify early markers of ASD. It is also possible to track the trajectories of children at risk of ASD to ascertain long-term neurodevelopmental outcomes and whether early behavioural markers are associated with later diagnostic classification.
Studies tracking siblings at risk of ASD have shown that the extent of their early difficulties is predictive of later social and behavioural problems and may also differentiate them from the siblings of typically developing children. For instance, in siblings of children with ASD, initial levels of joint attention (at 15 months) predicted the extent of social impairment and ASD diagnosis at 34 months [49] as well as language skills at age 5 [50]. In this same sample, 5year-old children with an ASD sibling showed vulnerabilities on measures of executive functioning, social cognition, and repetitive behaviour, as compared to siblings of typically developing children [51]. No group differences were found in various other domains measured at age 5 (i.e., global IQ, language, and behavioural problems). These results suggest that the siblings of children with ASD may demonstrate comparatively more problems in discrete neurocognitive domains but not others, even in the absence of an ASD diagnosis. Other research groups have reported similar findings [49, 52, 53]. In general, the presence of ASD characteristics (albeit at a less severe level) in the siblings of children with ASD has led to the widely accepted notion of a "broad ASD phenotype" [50], which is also consistent with dimensional approaches to diagnosis. New lines of evidence are emerging which suggest that the nonaffected siblings of individuals with ASD demonstrate similar patterns of activation in the neural regions underlying key social-communicative impairments of ASD, such as gaze fixation [51] and face processing [54]. These results suggest that these (and other) phenotypes may represent functional trait markers of genetic susceptibility to ASD and may be expressed broadly in the relatives of individuals with ASD.

Perhaps the greatest benefit of prospective studies of siblings of children with ASD is to determine the temporal onset of cognitive/behavioural problems in children who themselves go on to develop ASD. These infant sibling studies have revealed reliable differences in language [55], orienting to name [56], nonverbal problem solving [57], joint attention $[58,59]$, imitation, social smiling, and social affect $[60]$ in the second year of life. However, these and other studies [61] have generally failed to differentiate at-risk and non-at-risk children on the basis of cognitive and behavioural markers at 6 months or earlier, suggesting that social-cognitive abilities may be largely intact in the first year of life. Moreover, differences in social and communicative abilities may decline over the first 3 years of life in at-risk siblings who go on to develop ASD [62], suggesting a need to carefully track these siblings on a number of cognitive and behavioural markers early in development.

\subsection{Summary and Future Directions for ASD Sibling Research.} Studies employing sibling-based designs in the study of ASD have expanded our knowledge of the genetic epidemiology of the disorder and also help to clarify how genes and environments may operate in tandem in the pathogenesis of neurodevelopment. Twin designs suggest a high genetic contribution to ASD, a finding that is now well established. Further, research examining recurrence risk of ASD (either in twin or in nontwin siblings) suggests that not only is the degree of genetic relatedness associated with risk of ASD, but 
also environmental exposures may epigenetically regulate the expression of genes that modulate ASD symptomatology. In this regard, the joint circumstance of genetic vulnerability alongside exposure to teratogenic or neurotoxic agents may particularly predispose children to poor neurodevelopmental outcomes. Moreover, sibling studies that prospectively track infants have been useful in elucidating early markers of not only the risk of future ASD diagnosis, but also the risk of discrete neuropsychological skill deficits in the absence of ASD classification. The latter finding suggests that siblings of children with ASD may benefit from early prevention and monitoring.

While our knowledge of overall genetic and symptom risk related to ASD has been fostered by sibling studies, there remain gaps in our understanding of the discrete molecular genetic variants that create vulnerability to ASD among siblings, as well as how variability in neural functioning serves as an endophenotypic link between genetic risk and behavioural manifestations of the disorder. Future research in this area that compares $\mathrm{MZ}, \mathrm{DZ}$, nontwin full siblings, and half-siblings will shed light on whether the apparent gradient relationship between degree of genetic relatedness and risk of ASD also applies to cognitive processing and neural functioning that supports the behavioural and socialemotional faculties associated with ASD.

\section{Attention-Deficit Hyperactivity Disorder (ADHD)}

3.1. Overview of ADHD. ADHD is the most common childhood neurodevelopmental disorder, affecting approximately $5 \%$ of school-age children [63]. These prevalence estimates appear to have remained quite stable over time and are relatively ubiquitous across geographic location. According to the DSM-5, ADHD is characterized by a persistent pattern of inattention and/or hyperactivity/impulsivity. ADHD is associated with other cognitive impairments (i.e., executive functioning) [64] as well as a myriad of comorbid psychiatric problems across the lifespan [65-67], together causing significant impairment in academic, familial, and peer functioning. $\mathrm{ADHD}$, like ASD, represents a major public health concern, with impairing symptoms persisting into adulthood in $65 \%$ of individuals [68] and the pooled prevalence in adulthood of about $2.5 \%$ [69]. Thus, early identification and intervention are essential to alleviate the long-term effects of ADHD and its associated neuropsychiatric morbidities.

3.2. Sibling Studies of ADHD. ADHD has an overlapping yet distinct neurocognitive profile to ASD [70]. Despite this, the application of sibling designs to the study of ADHD, especially those examining recurrence rates and prospective tracking of infants, has been explored far less than in ASD. Nonetheless, the existing evidence is generally consistent with studies on ASD, which is helpful in understanding both the unity and the diversity of neurodevelopmental disorders.

3.2.1. Twin Designs of $A D H D$. Twin studies suggest that heritability of ADHD is high $\left(h^{2}=.75\right.$ to .91$)$, whether defined according to strict clinical cut-offs or along a broad phenotypic continuum $[71,72]$, with limited shared environmental effects. These results, like those of ASD, suggest that genetic liability for ADHD traits exists across the entire population. Moreover, research suggests that executive functioning, one of the key impairments in ADHD, is almost entirely genetic in origin and that liability towards ADHD strongly involves EF deficits $[73,74]$. In a sample of DZ twins discordant for ADHD diagnosis, it was shown that unaffected cotwins of children with ADHD were significantly impaired in many neuropsychological domains, including executive functioning, processing speed, and arousal regulation compared to controls, even after controlling for subclinical levels of ADHD symptoms [75]. These results suggest that neurocognitive deficits in these domains may serve as plausible endophenotypes in the etiology of ADHD. Although beyond the scope of this review, a number of molecular genetic studies have been conducted now which implicate many individual genes in the pathogenesis of ADHD [76,77]. These studies suggest that the same risk alleles that contribute to behavioural variability in the general population also confer risk of diagnosis of ADHD $[78,79]$.

As with studies of ASD, sibling designs suggest that genetic liabilities towards neurodevelopmental morbidities are likely mediated by neurocognitive functioning. For example, a twin study by Anokhin et al. [80] demonstrated that $60 \%$ of the variance in midfrontal (anterior cingulate cortex) activity is genetically mediated, suggesting that there may be heritable individual differences in neural processing related to neurobehavioural functioning (also see [81]). Among MZ twins, those with high levels of ADHD traits show volume loss in orbitofrontal and inferior dorsolateral prefrontal cortex [82]. Decreased activation in left dorsolateral prefrontal cortex and right parietal lobe has also been observed during executive processing tasks [83]. Together, these results suggest that different brain regions within a distributed network are influenced by genetic factors and may be related to neurocognitive markers of ADHD. On the other hand, recent imaging genetic studies suggest that while certain behavioural markers of ADHD may be to some extent heritable, the heritability of the functional neural networks that underlie these cognitive abilities is less certain [84]. More studies are needed to flesh out the meditational role of structural/functional neuroanatomy in the link between genetic variability and discrete cognitive impairments that underlie neurodevelopmental disorders.

3.2.2. Sibling Recurrence Rates of ADHD. The recurrence rate in nontwin siblings of children with $\mathrm{ADHD}$ has been shown to be about $13 \%$ [85] and as high as $30 \%$ [86], higher than population prevalence rates of 5\% [87]. Indeed, ADHD status is associated with sibling ADHD traits, whether measured narrowly or as a dimensional construct [85], suggesting that the siblings of children with ADHD may be at risk of developing not only ADHD, but also subclinical symptoms of the disorder [85]. Such genetic risk makes the study of siblings of affected children a viable channel for understanding pathways of neurodevelopment. 
3.2.3. Prospective Tracking of Infants at High Risk of ADHD. As with ASD, studies suggest that the siblings of children with $\mathrm{ADHD}$ are at a relatively higher risk of developing ADHD or related symptoms compared to those whose siblings do not have ADHD. For instance, Nigg et al. [88] showed that the parents and siblings of children with ADHD (especially combined type) were more likely to have an ADHD diagnosis compared to controls and had more neuropsychological impairments, even after controlling for parent/sibling ADHD status. On the other hand, prospective studies of at-risk children are relatively scarce compared to studies on ASD. In one notable study by Faraone and colleagues [89], siblings of children with ADHD showed significantly higher rates of disruptive behaviour, anxiety, depression, and schoolrelated difficulties compared to the siblings of non-ADHD children. These results corroborate early reports of the familygenetic risk of ADHD and intellectual impairment in the siblings of children with ADHD [90, 91]. They are also consistent with related avenues of research showing that the siblings of children with ADHD are at an increased risk of developing a host of other psychological and psychiatric problems, including disruptive behaviour problems [92, 93], affective disorders, and anxiety problems [89] compared to either control siblings or population prevalence rates.

Although genetic factors are highly implicated in the etiology of ADHD, environmental factors such as in utero chemical toxins, maternal smoking and substance use, low birth weight (a proxy for intrauterine nutrition and growth), and exposure to stress hormones are also operative [7, 94-98]. Psychosocial influences that index the home environment (e.g., quality of parental care, presence of learning materials, and family companionship) have also been shown to be associated with more ADHD-like symptoms in diagnosed children and, to a lesser degree, in their unaffected siblings. The mechanism through which these factors function has yet to be fully mapped, though epigenetic modification of gene expression remains a viable hypothesis $[5,7]$.

3.2.4. Neuropsychological/Cognitive Impairments of Siblings of Children with ADHD. Compared to the siblings of nonADHD controls, siblings of children with ADHD who themselves go on to develop ADHD have been shown to demonstrate more neuropsychological difficulties in the areas of attention, executive functioning, and memory [99]. In the latter study, the siblings of children with ADHD who themselves were not diagnosed scored similarly to the siblings of non-ADHD controls. These results suggest that perhaps siblings of children with severe ADHD and associated neuropsychological difficulties are at a particularly heightened risk of later difficulties [88]. However, it is likely that discrete difficulties in certain neurocognitive domains exist for the unaffected siblings of children with ADHD as well [100102]. For instance, unaffected siblings of children with ADHD are more impaired than controls across executive measures including inhibition, mental shifting, and verbal working memory $[100,102]$, as well as markers of motivational dysfunction (e.g., reaction time and action monitoring [103105]). On the other hand, a recent study showed that siblings of children with ADHD were not significantly different than controls on visual-spatial working memory [106]. Thus, similar to ASD, not only is the risk of developing clinical ADHD increased in the siblings of children with the disorder, but also siblings are at risk of showing deficits in a number of endophenotypic neurocognitive domains. Notably, there is evidence that siblings of children with ADHD may "grow out" of early executive deficits [107]. Future prospective studies that track large samples of siblings are needed to determine whether these trends hold for all children or whether there are different pathways to either discrete ADHD diagnosis or the neurocognitive endophenotypes that characterize ADHD.

Finally, it is interesting to note that familial risk of neurocognitive impairment not only is observed in twin studies (see above), but also has been reported in the nontwin siblings of children with ADHD. For instance, there is evidence that children with ADHD and their unaffected siblings demonstrate volume and/or activity reductions in prefrontal, occipital, and parietal regions compared to controls [108]. Further, genetic variability in the dopamine transporter gene (DAT1) has been associated with activation in the striatum and cerebellum in children with ADHD and their unaffected siblings [109]. These results suggest that the genetic liability to ADHD may manifest at the level of neural processing. However, determining when and how these neural and neurocognitive problems manifest at the level of disordered phenotypes is an area that requires further investigation. Indeed, it is plausible that there are multiple pathways to ADHD that rely on unique interactions between genetic and environmental dispositions and their resultant effects on brain development.

\subsection{Summary and Future Directions for ADHD Sibling} Research. Sibling research into ADHD suggests that this relatively common neurodevelopmental disorder is highly heritable and that subclinical or associated impairments may be present in the siblings of children with ADHD, even if a full-blown ADHD diagnosis is not warranted. Compared to research on ASD, the relative paucity of literature using sibling-based designs for ADHD provides important opportunities for future research.

Although early biological and behavioural manifestations of ADHD may have important implications for long-term outcomes [110], there are also a number of individuals with early symptoms of ADHD that resolve with time (i.e., desisters [111]). Given that ADHD symptoms do not in themselves predict developmental outcomes, other factors have the potential to support identification of children at risk of persistent problems [112]. For example, child (e.g., mood dysregulation and language delay) and environmental factors (e.g., parenting and parental mental health) have been associated with persistence of childhood ADHD symptoms [113, 114]. Prospective sibling-based designs allow researchers to explore the trajectory of children at risk as a function of other risk and moderating factors [115]. By comparing high-risk infants who do and do not develop ADHD on differentiating factors, we can further delineate the constitutional and/or environmental moderators that interact to influence the emergence, persistence, and remission of the disorder [116]. 


\section{Overlap between ASD and ADHD}

Although neurodevelopmental disorders are demarcated as discrete categories in the DSM-5 (in addition to earlier versions), emerging theoretical models and empirical evidence suggest a high degree of overlap between them. A recent review concluded that the cooccurrence of these disorders is high, with studies showing that $20-50 \%$ of children with ADHD display variable symptoms of ASD and $30-80 \%$ of children with ASD meet criteria for ADHD [117]. Recently, Pourcain and colleagues [118] used a general population sample to study the cooccurring developmental pathways of ADHD and the social communication domain of ASD. They found that over $70 \%$ of children in the impaired social communication group were part of the persistently high or moderate hyperactive-inattentive group, and over $80 \%$ of children with persistently high hyperactive-inattentive symptoms were included in the impaired social communication group. Further, there were shared prenatal/perinatal risks for social-communication and hyperactive-inattentive trajectories. Further, Cooper et al. [119] investigated 711 children diagnosed with ADHD who did not have an ASD diagnosis and found that children with ADHD who had higher levels of autistic symptomatology were more impaired in terms of severity of ADHD and various other domains of psychopathology and cognition. Notably, greater severity in comorbidities was seen after accounting for ADHD symptomatology, suggesting that elevation was related to characteristics of autism rather than being driven by severity of ADHD itself.

With respect to sibling designs specifically, twin studies suggest a moderate degree of overlap in genetic influences on ASD and ADHD traits, whether in the general population or in samples with clinically elevated symptoms [120-122]. In fact, up to $50-70 \%$ of the covariance between ASD and ADHD symptoms is explained by additive genetic factors in twin studies. A thorough delineation of the discrete genetic variants associated with both ASD and ADHD is outside the scope of this review, but interested readers may refer to recent empirical and review papers on this topic [123, 124]. Also, Table 1 summarizes several genes that have been implicated in both ASD and ADHD. Although we acknowledge that this list is not exhaustive, it offers a snapshot of the many molecular genetic studies that have been conducted on these disorders, albeit usually in separate investigations. Importantly, DSM-5 has removed ADHD as an exclusionary criterion for an ASD diagnosis, which should usher in a new generation of studies examining both the distinctiveness and the overlap of ASD and ADHD symptoms and whether these are explained by shared genetic or environmental influences.

Currently, sibling studies examining the occurrence of autism symptoms in children with ADHD show that ASD symptoms are more prevalent in children with ADHD than controls. For example, Mulligan et al. [125] examined autism symptoms in a sample consisting of 821 ADHD probands and 1050 siblings, as well as a control group of 149 families. Autism symptoms were higher in children with ADHD compared to siblings and normal controls, and interestingly, ASD symptoms were higher in the affected and unaffected male siblings of children with ADHD compared to controls. This overlap may be best explained at the level of specific cognitive endophenotypes that are shared across these neurodevelopmental disorders.

For instance, Rommelse et al. [126] showed that ASD traits were associated with $\mathrm{EF}$ and motor endophenotypes of ADHD, even after correction for ADHD diagnosis. Interestingly, sibling cross-correlations between $\mathrm{EF} /$ motor endophenotypes and ASD traits were also significant, suggesting that discrete familial factors which predispose to the neurocognitive deficits in ADHD may also underlie ASD symptomatology. Further, a recent study of 6,595 twins found support for one general genetic factor that accounted for a large proportion of the shared variance $(31 \%)$ in 53 neurodevelopmental problems characteristic of ASD, ADHD, and other disorders (e.g., motor control, perception, concentration, and tics) [127]. They found particularly high loadings for memory, autistic symptomatology, and ADHD traits. There were also three genetic subfactors specific to impulsivity, learning problems, and tics/autism, as well as three unique environmental factors for autism, hyperactivity and impulsivity, and inattention and learning problems. This study therefore suggests that a common heritable factor may be responsible for multiple neurocognitive problems that typify numerous neurodevelopmental disorders, yet there may also be unique genetic and environmental factors for certain problems. Future studies that elucidate the exact nature of these factors, especially distinct environmental contributors, may provide targets for how to best intervene to promote individual change and foster positive neurocognitive outcomes.

In sum, these varied studies using sibling methodology suggest that not only are ASD and ADHD related through common heritable factors, and perhaps relatively less strongly through environmental conditions, but also there may be specific symptoms that show overlap. Uncovering whether the nontwin siblings of children with particular ASD and ADHD traits also demonstrate increased crossover vulnerability to specific neurocognitive problems using prospective tracking designs is a ripe area for future research.

\section{Summary of Sibling Research on ASD and ADHD}

Taken together, the value of studying the siblings of children with neurodevelopmental conditions such as ASD and ADHD is the ability to (i) determine the relative contribution of genetic and nongenetic factors using twin designs; (ii) quantify the risk of development of these conditions by examining recurrence rates in siblings compared to control siblings or population prevalence rates; (iii) determine whether subclinical impairments in endophenotypes are present, such as social communication, executive functioning, and language, in the siblings of children with neurodevelopmental conditions; (iv) ascertain the risk of other cooccurring psychological/psychiatric conditions; (v) examine the developmental onset of various problems in atrisk siblings by prospectively tracking them and determining when early manifestations of these difficulties first emerge; 
TABLE 1: Summary of individual genes that have been implicated in both ASD and ADHD.

\begin{tabular}{|c|c|c|c|c|}
\hline \multirow{2}{*}{ Gene } & \multirow{2}{*}{ Chromosome } & \multirow{2}{*}{ Function } & \multicolumn{2}{|c|}{ Reference } \\
\hline & & & ASD & $\mathrm{ADHD}$ \\
\hline FMR1 (including premutation) & $\mathrm{Xq} 28$ & $\begin{array}{l}\text { Involved in making fragile } \mathrm{X} \text { mental retardation } 1 \text { protein }(\mathrm{FMRP}) \text {, an } \\
\text { RNA-binding protein involved in gene regulation }\end{array}$ & {$[150,151]$} & [151-153] \\
\hline TSC2 & $16 \mathrm{p} 13$ & $\begin{array}{l}\text { Actin cytoskeleton dynamics; inactivation of GTPase; neuronal } \\
\text { migration and cell differentiation }\end{array}$ & {$[154-156]$} & {$[157,158]$} \\
\hline$N F 1$ & 17q11 & $\begin{array}{l}\text { Codes for protein neurofibromin and causally related to } \\
\text { neurofibromatosis type 1; associated with inactivation of GTPase; } \\
\text { cytoskeleton dynamics }\end{array}$ & {$[159,160]$} & {$[161]$} \\
\hline SHANK3 & $22 \mathrm{q} 13$ & $\begin{array}{l}\text { Dendrite morphology regulation; synapse scaffolding and plasticity; } \\
\text { binding neuroligins }\end{array}$ & {$[162,163]$} & {$[164]$} \\
\hline GRIN2A & $16 \mathrm{p} 13$ & $\begin{array}{l}\text { Codes for the } 2 \mathrm{~A} \text { subunit of the NMDA receptor, which is ligand- and } \\
\text { voltage-gated and is involved in long-term potentiation and synaptic } \\
\text { transmission }\end{array}$ & {$[165]$} & {$[134,166]$} \\
\hline$G A B A R$ & $15 q 12$ & $\begin{array}{l}\text { Encodes the GABA receptors and their subunits, thus mediating } \\
\text { neurotransmitter inhibitory processes }\end{array}$ & {$[167,168]$} & {$[169,170]^{\mathrm{b}}$} \\
\hline SLC6A4/5HTT/SERT & $17 \mathrm{p} 11$ & $\begin{array}{l}\text { Encodes the serotonin transporter; mediates reuptake of serotonin } \\
\text { from synapses }\end{array}$ & {$[171,172]$} & {$[173,174]$} \\
\hline SLC6A3/DAT/DAT1 & & $\begin{array}{l}\text { Encodes a dopamine transporter; regulates extracellular dopamine } \\
\text { and reuptake of dopamine from synapses }\end{array}$ & {$[175,176]$} & {$[177,178]$} \\
\hline OXTR & $3 p 25-26$ & $\begin{array}{l}\text { Encodes the oxytocin receptor and thus mediates the action of } \\
\text { oxytocin in various brain regions, particularly those supporting social } \\
\text { cognition }\end{array}$ & {$[179,180]$} & {$[181]^{\mathrm{a}}$} \\
\hline$A V P R 1$ & $12 \mathrm{q} 14$ & $\begin{array}{l}\text { Encodes the arginine vasopressin receptor 1a, which mediates cell } \\
\text { contraction, proliferation, glycogenolysis, and platelet aggregation }\end{array}$ & {$[182,183]$} & {$[184]^{\mathrm{c}}$} \\
\hline SNAP25 & 20p12-p11.2 & $\begin{array}{l}\text { Encodes a plasma membrane protein involved in vesicle docking, } \\
\text { fusion, and neurotransmitter release }\end{array}$ & {$[185,186]$} & {$[178,187]$} \\
\hline SLC9A9/NHE9 & & $\begin{array}{l}\text { Encodes a sodium/proton exchanger; plays a role in cation } \\
\text { homeostasis }\end{array}$ & {$[188,189]$} & [190-192] \\
\hline HTR1B & $6 \mathrm{q} 13$ & $\begin{array}{l}\text { Encodes the 5-HT1B receptor, associated with serotonin regulation; } \\
\text { depending on location, it is variably involved in modulating serotonin } \\
\text { and dopamine in various cortical and noncortical regions }\end{array}$ & {$[193]$} & {$[194,195]$} \\
\hline NLGN4 & $\mathrm{Xp} 22.3$ & $\begin{array}{l}\text { Encodes protein neuroligin 4, involved in cell adhesion, synapse } \\
\text { formation, and mediates transsynaptic signalling }\end{array}$ & {$[196,197]$} & {$[198,199]$} \\
\hline DRD4 & $11 p 15.5$ & $\begin{array}{l}\text { Encodes dopamine receptor D4, a G-protein coupled receptor; upon } \\
\text { activation, the receptor inhibits adenylyl cyclase, thus decreasing } \\
\text { intracellular cyclic AMP }\end{array}$ & {$[200,201]^{\mathrm{d}}$} & {$[178,202]$} \\
\hline DRD5 & $4 \mathrm{p} 16.1$ & $\begin{array}{l}\text { Encodes dopamine receptor D5, which is involved in synthesis of } \\
\text { cyclic AMP via activation of adenylyl cyclase, and } \mathrm{Ca}^{2+} \text { and } \mathrm{K}^{+} \\
\text {conductance }\end{array}$ & {$[203]^{\mathrm{e}}$} & {$[178,204]$} \\
\hline DRD3 & $3 q 13.3$ & $\begin{array}{l}\text { Encodes dopamine receptor D3; activity is mediated by G-proteins } \\
\text { which inhibit adenylyl cyclase; promotes cell proliferation }\end{array}$ & {$[205,206]$} & [207] \\
\hline$M A O A$ & Xp11.3 & $\begin{array}{l}\text { Encodes enzymes that deaminate and catabolize neurotransmitters } \\
\text { such as dopamine, serotonin, and norepinephrine }\end{array}$ & [208-210] & {$[211,212]$} \\
\hline COMT & $22 \mathrm{q} 11.21$ & $\begin{array}{l}\text { Encodes the catechol-O-methyltransferase enzyme, which catabolizes } \\
\text { neurotransmitters such as dopamine and norepinephrine }\end{array}$ & {$[213,214]$} & {$[215,216]$} \\
\hline
\end{tabular}

${ }^{\mathrm{a}}$ Findings should be considered preliminary.

${ }^{\mathrm{b}}$ In this study, OXTR was only associated with social cognition in ADHD and not diagnostic status itself.

${ }^{\mathrm{c}}$ In this study, AVPRIA was associated with executive functioning, not ADHD, although executive functioning is considered a core impairment in ADHD (but also other neurodevelopmental conditions, including autism).

${ }^{\mathrm{d}}$ Results may reflect differences in cooccurring symptoms among individuals with ASD as opposed to diagnosis of ASD specifically.

${ }^{\mathrm{e}} \mathrm{Few}$ studies have shown similar results, so these should be interpreted cautiously. 
(vi) identify potential moderating factors that serve to protect children showing early manifestations of difficulties; and (vii) understand the nature of comorbidity and symptom overlap of neurodevelopmental disorders, including how nonspecific neurocognitive traits contribute to various disorders and which neurocognitive traits are explained by common genetic and/or environmental factors. On aggregate, these findings point to a need for appropriate prevention programs in order to reduce the risk of later problems.

\section{Prevention Programming for At-Risk Children}

Clinically, the ability to identify children at risk of later difficulties (whether disordered in the typical vein or showing relative impairment across the spectrum of symptoms) enables researchers, clinicians, and policymakers to determine who to target for primary prevention given scant societal resources. We know from the above studies that siblings of children with ASD and ADHD represent a subpopulation of children who are vulnerable to suboptimal social, emotional, cognitive, and psychiatric outcomes. We also know that, for ASD in particular, while differentiation of siblings who experience later problems within the first year of life is difficult, there is a constellation of phenotypes that emerge after 12 months that may be key markers of later difficulties. Importantly, there does not appear to be a single atypical behaviour that reliably predicts later neurodevelopmental problems [128]. Rather, there is a heterogeneous set of socialcommunicative, motor, executive, and sensory behaviours that together predict later diagnosis, all of which need to be considered in prevention efforts.

Prospective studies $[55,60,61]$ of children at risk of later problems demonstrate the feasibility of detecting early warning signs through intensive monitoring. Organizations (e.g., American Academy of Pediatrics) have spelled out specific guidelines for the early identification, screening, and diagnosis of neurodevelopmental disabilities, including the suggestion that all children aged 18-24 months be screened for early onset signs [129]. However, the peak for diagnoses of ASD and ADHD is in middle childhood (4-7 years $[130,131])$, and the availability of reliable and valid tools for use in children under 3 years remains scarce. Reliance on retrospective parental reports and child histories alone tells a very different story about the development and decline in social communication than prospective surveillance is capable of [62]. These findings speak to the need for active and repeated assessment and discussion about parental concerns [132], as well as the incorporation of developmental observation during regular primary healthcare visits [133]. Although screening tools (e.g., Checklist for Autism in Toddlers [134]) for early signs of atypicality can be used with children under the age of 2 (especially when combined with other surveillance methods), these are rarely used in medical practices [135]. Early screening is particularly indicated for siblings of children with ASD and ADHD, given that they are at higher risk of these and other neurodevelopmental conditions.
Access to early intervention services for those determined to be at risk, by virtue of their family history, genetic disposition, and/or early assessment, is critical to alleviating the burden of neurodevelopmental morbidity on children, families, and society. However, the current state of services for infants and toddlers suspected to have these conditions is limited. Fostering the ability of parents and caregivers to respond sensitively and contingently may be particularly useful for children's emotional, social, and cognitive development [136], an effect that likely holds for both at-risk and typically developing children. For children (including siblings) at risk of neurodevelopmental disorders, interventions that incorporate specific skill building in joint attention, intentional communication with language and gesture, symbolic and reciprocal play, and imitative interactions may be fruitful given that these tend to be areas of difficulty for these children. Importantly, these should be provided in the context of naturalistic environments that involve responsive caregiving, enriched language, and reciprocal interactions that may mitigate the decline in neurodevelopment of at-risk children and foster the functional traits that are critical for psychosocial health and development $[132,137]$.

Delineating early markers of the emergence and persistence of ASD and ADHD through sibling studies has implications for preventive and early intervention efforts. Infancy and early childhood represent a time of heightened neurobiological sensitivity (i.e., brain plasticity) and thus interventions during this period may have a lasting impact. Additionally, early intervention may serve to derail the onset of maladaptive behavioural patterns associated with symptomatology (e.g., coercive parent-child interactions) and can also support families prior to the formation of negative assumptions and attitudes associated with full symptomatology.

Specific examples of intervention programs for children at risk of neurodevelopmental disorders, defined as being a younger sibling of a child with a neurodevelopmental disorder, are sparse. In fact, we know of none for children at risk of $\mathrm{ADHD}$ and could identify only a handful of intervention studies for children at risk of ASD. Three of these were small studies with less than 10 participants: one was a case series of seven siblings of children with ASD [138], while two used multiple-baseline designs of three participants $[139,140]$. The best example of parent-mediated interventions for children at familial risk of ASD is captured in a recent study by Green and colleagues [141]. The program was a two-site, two-arm prevention randomized control trial of 54 families (28 intervention; 26 control) of 7-10-month-old infants who had an older sibling with ASD. The intervention was a modification of the Video Interaction for Promoting Positive Parenting program (VIPP [142]), a program that uses video feedback to help parents adjust their parenting styles to the needs of their child to promote positive social and communicative development. The program consisted of six sessions with an additional six booster sessions depending on family needs. Results showed moderate to strong intervention effects on children's attentiveness to their parents, autism-risk behaviours (e.g., behavioural atypicality), attentional disengagement, and parent-reported social-adaptive functioning. Concomitant improvements in parental nondirectiveness 
(but not sensitivity or mutuality) were also seen. No positive effects for language or responsivity to vowel change were shown. Overall, these results suggest that parent-child interaction-focused interventions may modify the emergence of established behavioural markers of ASD. Moreover, these results are consistent with the general suggestion that early intervention, particularly within the first two years of life, can significantly alter the developmental trajectory of high-risk infants [143].

\section{Conclusions}

Our understanding of neurodevelopmental disorders has increased dramatically over the last four decades, and sibling designs have been instrumental in elucidating the complex and heterogeneous pathways to neurodevelopmental functioning. Twin, recurrence risk, and prospective tracking studies have not only improved our understanding of the etiology of neurodevelopmental conditions but also bolstered our capacity to identify children at risk of particular conditions in order to effectively intervene before the emergence of stable and severe levels of difficulty requires costly remediation. Findings from high-risk sibling studies may thus serve to inform universal screening procedures that could be implemented in primary care settings. These studies could, for example, aid in the development of a risk index that reliably identifies children who could be effectively targeted with early intervention approaches [116]. Once identified, individuals and their families can be referred for treatment services. Child-directed services that target individual profiles may opt to build cognitive skills such as working memory, attention, self-regulation, or social-emotional and communication skills, and there are currently many programs tailored towards such skill building [144-149]. Determining how to successfully adapt these programs to at-risk children who demonstrate subclinical or prodromal symptoms is an area that requires future investigation. Moreover, familylevel interventions may support parents to promote cognitive training and/or target parent-child interactional patterns. Such programs are currently being evaluated for children at risk of ASD, and determining whether comparable programs show utility in buffering against ADHD risk is an important question for clinical researchers. As our understanding of the genetic and environmental underpinnings of these disorders continues to expand, movement from targeted to universal screening and intervention may prove feasible, and sibling designs will have undoubtedly served to steer us in the right direction.

\section{Conflict of Interests}

The authors declare that there is no conflict of interests regarding the publication of this paper.

\section{References}

[1] S. Goldstein and C. R. Reynolds, Handbook of Neurodevelopmental and Genetic Disorders in Children, 2/e, Guilford Press, 2010.
[2] R. Taurines, C. Schwenck, E. Westerwald, M. Sachse, M. Siniatchkin, and C. Freitag, "ADHD and autism: differential diagnosis or overlapping traits? A selective review," $A D H D$ Attention Deficit and Hyperactivity Disorders, vol. 4, no. 3, pp. 115-139, 2012.

[3] A. Thapar, K. Langley, P. Asherson, and M. Gill, "Geneenvironment interplay in attention-deficit hyperactivity disorder and the importance of a developmental perspective," The British Journal of Psychiatry, vol. 190, no. 1, pp. 1-3, 2007.

[4] J. Hallmayer, S. Cleveland, A. Torres et al., "Genetic heritability and shared environmental factors among twin pairs with autism," Archives of General Psychiatry, vol. 68, no. 11, pp. 10951102, 2011.

[5] P. J. Landrigan, L. Lambertini, and L. S. Birnbaum, "A research strategy to discover the environmental causes of autism and neurodevelopmental disabilities," Environmental Health Perspectives, vol. 120, no. 7, pp. a258-a260, 2012.

[6] P. J. Landrigan, "What causes autism? Exploring the environmental contribution," Current Opinion in Pediatrics, vol. 22, no. 2, pp. 219-225, 2010.

[7] J. Mill and A. Petronis, "Pre- and peri-natal environmental risks for attention-deficit hyperactivity disorder (ADHD): the potential role of epigenetic processes in mediating susceptibility," Journal of Child Psychology and Psychiatry, vol. 49, no. 10, pp. 1020-1030, 2008.

[8] R. K. Lenroot and J. N. Giedd, "The changing impact of genes and environment on brain development during childhood and adolescence: initial findings from a neuroimaging study of pediatric twins," Development and Psychopathology, vol. 20, no. 4, pp. 1161-1175, 2008.

[9] M. L. Ganz, "The lifetime distribution of the incremental societal costs of autism," Archives of Pediatrics and Adolescent Medicine, vol. 161, no. 4, pp. 343-349, 2007.

[10] T. A. Lavelle, M. C. Weinstein, J. P. Newhouse, K. Munir, K. A. Kuhlthau, and L. A. Prosser, "Economic burden of childhood autism spectrum disorders," Pediatrics, vol. 133, no. 3, pp. e520e529, 2014.

[11] T. T. Shimabukuro, S. D. Grosse, and C. Rice, "Medical expenditures for children with an autism spectrum disorder in a privately insured population," Journal of Autism and Developmental Disorders, vol. 38, no. 3, pp. 546-552, 2008.

[12] J. A. Doshi, P. Hodgkins, J. Kahle et al., "Economic impact of childhood and adult attention-deficit/hyperactivity disorder in the United States," Journal of the American Academy of Child \& Adolescent Psychiatry, vol. 51, no. 10, pp. 990.e2-1002.e2, 2012.

[13] K. Secnik, A. Swensen, and M. J. Lage, "Comorbidities and costs of adult patients diagnosed with attention-deficit hyperactivity disorder," PharmacoEconomics, vol. 23, no. 1, pp. 93-102, 2005.

[14] A. R. Swensen, H. G. Birnbaum, K. Secnik, M. Marynchenko, P. Greenberg, and A. Claxton, "Attention-deficit/hyperactivity disorder: increased costs for patients and their families," Journal of the American Academy of Child \& Adolescent Psychiatry, vol. 42, no. 12, pp. 1415-1423, 2003.

[15] P. Howlin, S. Goode, J. Hutton, and M. Rutter, "Adult outcome for children with autism," Journal of Child Psychology and Psychiatry and Allied Disciplines, vol. 45, no. 2, pp. 212-229, 2004.

[16] R. A. Barkley, M. Fischer, C. S. Edelbrock, and L. Smallish, "The adolescent outcome of hyperactive children diagnosed by research criteria: I. An 8-year prospective follow-up study," Journal of the American Academy of Child \& Adolescent Psychiatry, vol. 29 , no. 4 , pp. 546-557, 1990. 
[17] R. A. Lasser, D. W. Goodman, P. Asherson et al., "Lifespan persistence of ADHD: the life transition model and its application," Journal of Clinical Psychiatry, vol. 73, no. 2, pp. 192-201, 2012.

[18] S. M. Myers and C. P. Johnson, "Management of children with autism spectrum disorders," Pediatrics, vol. 120, no. 5, pp. 11621182, 2007.

[19] C. Rice, "Prevalence of autism spectrum disorders: autism and developmental disabilities monitoring network, United States, 2006," Morbidity and Mortality Weekly Report-Surveillance Summaries, vol. 58, no. SS10, pp. 1-20, 2009.

[20] J. Baio, "Prevalence of autism spectrum disorders-autism and developmental disabilities monitoring network, 14 sites, United States, 2008," Morbidity and Mortality Weekly Report. Surveillance Summaries, vol. 61, no. 3, pp. 1-19, 2012.

[21] Y. S. Kim, B. L. Leventhal, Y. J. Koh et al., "Prevalence of autism spectrum disorders in a total population sample," American Journal of Psychiatry, vol. 168, no. 9, pp. 904-912, 2012.

[22] S. Chakrabarti and E. Fombonne, "Pervasive developmental disorders in preschool children: confirmation of high prevalence," American Journal of Psychiatry, vol. 162, no. 6, pp. 11331141, 2005.

[23] E. Fombonne, "Epidemiological surveys of autism and other pervasive developmental disorders: an update," Journal of Autism and Developmental Disorders, vol. 33, no. 4, pp. 365-382, 2003.

[24] E. Fombonne, "The prevalence of autism," Journal of the American Medical Association, vol. 289, no. 1, pp. 87-89, 2003.

[25] L. Wing, J. Gould, and C. Gillberg, "Autism spectrum disorders in the DSM-V: better or worse than the DSM-IV?" Research in Developmental Disabilities, vol. 32, no. 2, pp. 768-773, 2011.

[26] J. N. Constantino and R. D. Todd, "Autistic traits in the general population: a twin study," Archives of General Psychiatry, vol. 60, no. 5, pp. 524-530, 2003.

[27] R. E. Rosenberg, J. K. Law, G. Yenokyan, J. McGready, W. E. Kaufmann, and P. A. Law, "Characteristics and concordance of autism spectrum disorders among 277 twin pairs," Archives of Pediatrics and Adolescent Medicine, vol. 163, no. 10, pp. 907-914, 2009.

[28] A. Bailey, A. Le Couteur, I. Gottesman et al., "Autism as a strongly genetic disorder: evidence from a British twin study," Psychological Medicine, vol. 25, no. 1, pp. 63-77, 1995.

[29] A. Ronald, F. Happé, P. Bolton et al., "Genetic heterogeneity between the three components of the autism spectrum: a twin study," Journal of the American Academy of Child \& Adolescent Psychiatry, vol. 45, no. 6, pp. 691-699, 2006.

[30] P. Bolton, H. Macdonald, A. Pickles et al., "A case-control family history study of autism," Journal of Child Psychology and Psychiatry, vol. 35, no. 5, pp. 877-900, 1994.

[31] A. M. Persico and T. Bourgeron, "Searching for ways out of the autism maze: genetic, epigenetic and environmental clues," Trends in Neurosciences, vol. 29, no. 7, pp. 349-358, 2006.

[32] W. R. Kates, C. P. Burnette, S. Eliez et al., "Neuroanatomic variation in monozygotic twin pairs discordant for the narrow phenotype for autism," The American Journal of Psychiatry, vol. 161, no. 3, pp. 539-546, 2004.

[33] S. R. Mitchell, A. L. Reiss, D. H. Tatusko et al., "Neuroanatomic alterations and social and communication deficits in monozygotic twins discordant for autism disorder," American Journal of Psychiatry, vol. 166, no. 8, pp. 917-925, 2009.

[34] H. V. Bohm and M. G. Stewart, "Brief report: on the concordance percentages for autistic spectrum disorder of Twins,"
Journal of Autism and Developmental Disorders, vol. 39, no. 5, pp. 806-808, 2009.

[35] D. H. Geschwind, "Genetics of autism spectrum disorders," Trends in Cognitive Sciences, vol. 15, no. 9, pp. 409-416, 2011.

[36] S. Ozonoff, G. S. Young, A. Carter et al., "Recurrence risk for autism spectrum disorders: a Baby Siblings Research Consortium study," Pediatrics, vol. 128, no. 3, pp. e488-e495, 2011.

[37] S. J. Rogers, "What are infant siblings teaching us about autism in infancy?" Autism Research, vol. 2, no. 3, pp. 125-137, 2009.

[38] J. N. Constantino, Y. Zhang, T. Frazier, A. M. Abbacchi, and P. Law, "Sibling recurrence and the genetic epidemiology of autism," The American Journal of Psychiatry, vol. 167, no. 11, pp. 1349-1356, 2010.

[39] J. N. Constantino, A. Todorov, C. Hilton et al., "Autism recurrence in half siblings: strong support for genetic mechanisms of transmission in ASD," Molecular Psychiatry, vol. 18, no. 2, pp. 137-138, 2013.

[40] N. Risch, T. J. Hoffmann, M. Anderson, L. A. Croen, J. K. Grether, and G. C. Windham, "Familial recurrence of autism spectrum disorder: evaluating genetic and environmental contributions," American Journal of Psychiatry, vol. 171, no. 11, pp. 1206-1213, 2014.

[41] T. L. Arndt, C. J. Stodgell, and P. M. Rodier, "The teratology of autism," International Journal of Developmental Neuroscience, vol. 23, no. 2-3, pp. 189-199, 2005.

[42] K. Stromland, V. Nordin, M. Miller, B. Akerstrom, and C. Gillberg, "Autism in thalidomide embryopathy: a population study," Developmental Medicine \& Child Neurology, vol. 36, no. 4, pp. 351-356, 1994.

[43] Y. Yamashita, C. Fujimoto, E. Nakajima, T. Isagai, and T. Matsuishi, "Possible association between congenital cytomegalovirus infection and autistic disorder," Journal of Autism and Developmental Disorders, vol. 33, no. 4, pp. 455-459, 2003.

[44] B. Eskenazi, A. R. Marks, A. Bradman et al., "Organophosphate pesticide exposure and neurodevelopment in young MexicanAmerican children," Environmental Health Perspectives, vol. 115, no. 5, pp. 792-798, 2007.

[45] A. Miodovnik, S. M. Engel, C. Zhu et al., "Endocrine disruptors and childhood social impairment," NeuroToxicology, vol. 32, no. 2, pp. 261-267, 2011.

[46] A. M. Persico and S. Merelli, "Environmental factors in the onset of autism spectrum disorder," Current Developmental Disorders Reports, vol. 1, no. 1, pp. 8-19, 2014.

[47] D. Dufour-Rainfray, P. Vourc'h, S. Tourlet, D. Guilloteau, S. Chalon, and C. R. Andres, "Fetal exposure to teratogens: evidence of genes involved in autism," Neuroscience \& Biobehavioral Reviews, vol. 35, no. 5, pp. 1254-1265, 2011.

[48] K. Mevel, P. Fransson, and S. Bölte, "Multimodal brain imaging in autism spectrum disorder and the promise of twin research," Autism, vol. 19, no. 5, pp. 527-541, 2015.

[49] N. Yirmiya, I. Gamliel, M. Shaked, and M. Sigman, "Cognitive and verbal abilities of 24- to 36-month-old siblings of children with autism," Journal of Autism and Developmental Disorders, vol. 37, no. 2, pp. 218-229, 2007.

[50] J. Piven, P. Palmer, D. Jacobi, D. Childress, and S. Arndt, "Broader autism phenotype: evidence from a family history study of multiple-incidence autism families," The American Journal of Psychiatry, vol. 154, no. 2, pp. 185-190, 1997.

[51] K. M. Dalton, B. M. Nacewicz, A. L. Alexander, and R. J. Davidson, "Gaze-fixation, brain activation, and amygdala volume in unaffected siblings of individuals with autism," Biological Psychiatry, vol. 61, no. 4, pp. 512-520, 2007. 
[52] I. Gamliel, N. Yirmiya, D. H. Jaffe, O. Manor, and M. Sigman, "Developmental trajectories in siblings of children with autism: cognition and language from 4 months to 7 years," Journal of Autism and Developmental Disorders, vol. 39, no. 8, pp. 11311144, 2009.

[53] I. Gamliel, N. Yirmiya, and M. Sigman, "The development of young siblings of children with autism from 4 to 54 months," Journal of Autism and Developmental Disorders, vol. 37, no. 1, pp. 171-183, 2007.

[54] G. Dawson, S. J. Webb, E. Wijsman et al., "Neurocognitive and electrophysiological evidence of altered face processing in parents of children with autism: implications for a model of abnormal development of social brain circuitry in autism," Development and Psychopathology, vol. 17, no. 3, pp. 679-697, 2005.

[55] R. Landa and E. Garrett-Mayer, "Development in infants with autism spectrum disorders: a prospective study," Journal of Child Psychology and Psychiatry and Allied Disciplines, vol. 47, no. 6, pp. 629-638, 2006.

[56] A. Nadig, S. Ozonoff, G. S. Young, A. Rozga, M. Sigman, and S. J. Rogers, "Failure to respond to name is an indicator of possible autism spectrum disorder," Archives of Pediatrics and Adolescent Medicine, vol. 161, pp. 378-383, 2007.

[57] W. L. Stone, C. R. McMahon, P. J. Yoder, and T. A. Walden, "Early social-communicative and cognitive development of younger siblings of children with autism spectrum disorders," Archives of Pediatrics \& Adolescent Medicine, vol. 161, no. 4, pp. 384-390, 2007.

[58] N. Yirmiya, I. Gamliel, T. Pilowsky, R. Feldman, S. BaronCohen, and M. Sigman, "The development of siblings of children with autism at 4 and 14 months: social engagement, communication, and cognition," Journal of Child Psychology and Psychiatry, vol. 47, no. 5, pp. 511-523, 2006.

[59] T. D. Cassel, D. S. Messinger, L. V. Ibanez, J. D. Haltigan, S. I. Acosta, and A. C. Buchman, "Early social and emotional communication in the infant siblings of children with autism spectrum disorders: an examination of the broad phenotype," Journal of Autism and Developmental Disorders, vol. 37, no. 1, pp. 122-132, 2007.

[60] L. Zwaigenbaum, S. Bryson, T. Rogers, W. Roberts, J. Brian, and P. Szatmari, "Behavioral manifestations of autism in the first year of life," International Journal of Developmental Neuroscience, vol. 23, no. 2-3, pp. 143-152, 2005.

[61] S. E. Bryson, L. Zwaigenbaum, J. Brian et al., "A prospective case series of high-risk infants who developed autism," Journal of Autism and Developmental Disorders, vol. 37, no. 1, pp. 12-24, 2007.

[62] S. Ozonoff, A.-M. Iosif, F. Baguio et al., "A prospective study of the emergence of early behavioral signs of autism," Journal of the American Academy of Child \& Adolescent Psychiatry, vol. 49, no. 3, pp. 256.e1-2-266.el-2, 2010.

[63] G. V. Polanczyk, E. G. Willcutt, G. A. Salum, C. Kieling, and L. A. Rohde, "ADHD prevalence estimates across three decades: an updated systematic review and meta-regression analysis," International Journal of Epidemiology, vol. 43, no. 2, pp. 434442, 2014.

[64] E. G. Willcutt, A. E. Doyle, J. T. Nigg, S. V. Faraone, and B. F. Pennington, "Validity of the executive function theory of attention-deficit/hyperactivity disorder: a meta-analytic review," Biological Psychiatry, vol. 57, no. 11, pp. 1336-1346, 2005.
[65] J. Biederman, "Attention-deficit/hyperactivity disorder: a selective overview," Biological Psychiatry, vol. 57, no. 11, pp. 1215-1220, 2005.

[66] E. J. Mash and R. A. Barkley, Assessment of Childhood Disorders, Guilford Press, 2009.

[67] S. Cortese, S. V. Faraone, E. Konofal, and M. Lecendreux, "Sleep in children with attention-deficit/hyperactivity disorder: meta-analysis of subjective and objective studies," Journal of the American Academy of Child \& Adolescent Psychiatry, vol. 48, no. 9, pp. 894-908, 2009.

[68] S. V. Faraone, J. Biederman, and E. Mick, "The age-dependent decline of attention deficit hyperactivity disorder: a metaanalysis of follow-up studies," Psychological Medicine, vol. 36, no. 2, pp. 159-165, 2006.

[69] V. Simon, P. Czobor, S. Bálint, Á. Mészáros, and I. Bitter, "Prevalence and correlates of adult attention-deficit hyperactivity disorder: meta-analysis," British Journal of Psychiatry, vol. 194, no. 3, pp. 204-211, 2009.

[70] S. Ozonoff, B. F. Pennington, and S. J. Rogers, "Executive function deficits in high-functioning autistic individuals: relationship to theory of mind," Journal of Child Psychology and Psychiatry and Allied Disciplines, vol. 32, no. 7, pp. 1081-1105, 1991.

[71] J.-O. Larsson, H. Larsson, and P. Lichtenstein, "Genetic and environmental contributions to stability and change of ADHD symptoms between 8 and 13 years of age: a longitudinal twin study," Journal of the American Academy of Child \& Adolescent Psychiatry, vol. 43, no. 10, pp. 1267-1275, 2004.

[72] F. Levy, D. A. Hay, M. McStephen, C. Wood, and I. Waldman, "Attention-deficit hyperactivity disorder: a category or a continuum? Genetic analysis of a large-scale twin study," Journal of the American Academy of Child \& Adolescent Psychiatry, vol. 36, no. 6, pp. 737-744, 1997.

[73] N. P. Friedman, A. Miyake, S. E. Young, J. C. DeFries, R. P. Corley, and J. K. Hewitt, "Individual differences in executive functions are almost entirely genetic in origin," Journal of Experimental Psychology: General, vol. 137, no. 2, pp. 201-225, 2008.

[74] F. L. Coolidge, L. L. Thede, and S. E. Young, "Heritability and the comorbidity of attention deficit hyperactivity disorder with behavioral disorders and executive function deficits: a preliminary investigation," Developmental Neuropsychology, vol. 17, no. 3, pp. 273-287, 2000.

[75] L. C. Bidwell, E. G. Willcutt, J. C. DeFries, and B. F. Pennington, "Testing for neuropsychological endophenotypes in siblings discordant for attention-deficit/hyperactivity disorder," Biological Psychiatry, vol. 62, no. 9, pp. 991-998, 2007.

[76] S. V. Faraone, R. H. Perlis, A. E. Doyle et al., "Molecular genetics of attention-deficit/hyperactivity disorder," Biological Psychiatry, vol. 57, no. 11, pp. 1313-1323, 2005.

[77] Z. Li, S.-H. Chang, L.-Y. Zhang, L. Gao, and J. Wang, "Molecular genetic studies of ADHD and its candidate genes: a review," Psychiatry Research, vol. 219, no. 1, pp. 10-24, 2014.

[78] E. Stergiakouli, J. Martin, M. Hamshere et al., "Shared genetic influences between attention-deficit/hyperactivity disorder (ADHD) traits in children and clinical ADHD," Journal of the American Academy of Child \& Adolescent Psychiatry, vol. 54, no. 4, pp. 322-327, 2015.

[79] J. Martin, M. L. Hamshere, E. Stergiakouli, M. C. O’Donovan, and A. Thapar, "Genetic risk for attention-deficit/hyperactivity 
disorder contributes to neurodevelopmental traits in the general population," Biological Psychiatry, vol. 76, no. 8, pp. 664671, 2014.

[80] A. P. Anokhin, A. C. Heath, and E. Myers, "Genetics, prefrontal cortex, and cognitive control: a twin study of event-related brain potentials in a response inhibition task," Neuroscience Letters, vol. 368, no. 3, pp. 314-318, 2004.

[81] A. P. Anokhin, S. Golosheykin, and A. C. Heath, "Heritability of frontal brain function related to action monitoring," Psychophysiology, vol. 45, no. 4, pp. 524-534, 2008.

[82] D. van't Ent, H. Lehn, E. M. Derks et al., "A structural MRI study in monozygotic twins concordant or discordant for attention/hyperactivity problems: evidence for genetic and environmental heterogeneity in the developing brain," NeuroImage, vol. 35, no. 3, pp. 1004-1020, 2007.

[83] D. Van’t Ent, C. E. M. van Beijsterveldt, E. M. Derks et al., "Neuroimaging of response interference in twins concordant or discordant for inattention and hyperactivity symptoms," Neuroscience, vol. 164, no. 1, pp. 16-29, 2009.

[84] C. Macare, T. Meindl, I. Nenadic, D. Rujescu, and U. Ettinger, "Preliminary findings on the heritability of the neural correlates of response inhibition," Biological Psychology, vol. 103, pp. 19-23, 2014.

[85] W. Chen, K. Zhou, P. Sham et al., "DSM-IV combined type ADHD shows familial association with sibling trait scores: a sampling strategy for QTL linkage," The American Journal of Medical Genetics Part B: Neuropsychiatric Genetics, vol. 147, no. 8, pp. 1450-1460, 2008.

[86] N. Ma, R. Roberts, H. Winefield, and G. Furber, “The prevalence of psychopathology in siblings of children with mental health problems: a 20-year systematic review," Child Psychiatry \& Human Development, vol. 46, no. 1, pp. 130-149, 2015.

[87] G. Polanczyk, M. S. de Lima, B. L. Horta, J. Biederman, and L. A. Rohde, "The worldwide prevalence of ADHD: a systematic review and metaregression analysis," American Journal of Psychiatry, vol. 164, no. 6, pp. 942-948, 2007.

[88] J. T. Nigg, L. G. Blaskey, J. A. Stawicki, and J. Sachek, "Evaluating the endophenotype model of ADHD neuropsychological deficit: results for parents and siblings of children with ADHD combined and inattentive subtypes," Journal of Abnormal Psychology, vol. 113, no. 4, pp. 614-625, 2004.

[89] S. V. Faraone, J. Biederman, D. Mennin, J. Gershon, and M. T. Tsuang, "A prospective four-year follow-up study of children at risk for ADHD: psychiatric, neuropsychological, and psychosocial outcome," Journal of the American Academy of Child \& Adolescent Psychiatry, vol. 35, no. 11, pp. 1449-1459, 1996.

[90] J. Biederman, S. V. Faraone, K. Keenan, D. Knee, and M. T. Tsuang, "Family-genetic and psychosocial risk factors in DSMIII attention deficit disorder," Journal of the American Academy of Child \& Adolescent Psychiatry, vol. 29, no. 4, pp. 526-533, 1990.

[91] S. V. Faraone, J. Biederman, B. K. Lehman et al., "Intellectual performance and school failure in children with attention deficit hyperactivity disorder and in their siblings," Journal of Abnormal Psychology, vol. 102, no. 4, pp. 616-623, 1993.

[92] E. Sobanski, T. Banaschewski, P. Asherson et al., "Emotional lability in children and adolescents with attention deficit/hyperactivity disorder (ADHD): clinical correlates and familial prevalence," Journal of Child Psychology and Psychiatry and Allied Disciplines, vol. 51, no. 8, pp. 915-923, 2010.
[93] H. Christiansen, W. Chen, R. D. Oades et al., "Co-transmission of conduct problems with attention-deficit/hyperactivity disorder: familial evidence for a distinct disorder," Journal of Neural Transmission, vol. 115, no. 2, pp. 163-175, 2008.

[94] T. E. Froehlich, B. P. Lanphear, P. Auinger et al., "Association of tobacco and lead exposures with attention-deficit/ hyperactivity disorder," Pediatrics, vol. 124, no. 6, pp. e1054-e1063, 2009.

[95] S. K. Sagiv, S. W. Thurston, D. C. Bellinger, C. Amarasiriwardena, and S. A. Korrick, "Prenatal exposure to mercury and fish consumption during pregnancy and attentiondeficit/hyperactivity disorder-related behavior in children," Archives of Pediatrics \& Adolescent Medicine, vol. 166, no. 12, pp. 1123-1131, 2012.

[96] L. London, C. Beseler, M. F. Bouchard et al., "Neurobehavioral and neurodevelopmental effects of pesticide exposures," NeuroToxicology, vol. 33, no. 4, pp. 887-896, 2012.

[97] G. Winneke, "Developmental aspects of environmental neurotoxicology: lessons from lead and polychlorinated biphenyls," Journal of the Neurological Sciences, vol. 308, no. 1-2, pp. 9-15, 2011.

[98] T. D. Banerjee, F. Middleton, and S. V. Faraone, "Environmental risk factors for attention-deficit hyperactivity disorder," Acta Paediatrica, vol. 96, no. 9, pp. 1269-1274, 2007.

[99] L. J. Seidman, J. Biederman, M. C. Monuteaux, W. Weber, and S. V. Faraone, "Neuropsychological functioning in nonreferred siblings of children with attention deficit/hyperactivity disorder," Journal of Abnormal Psychology, vol. 109, no. 2, pp. 252-265, 2000.

[100] N. N. J. Rommelse, M. E. Altink, J. Oosterlaan, C. J. M. Buschgens, J. Buitelaar, and J. A. Sergeant, "Support for an independent familial segregation of executive and intelligence endophenotypes in ADHD families," Psychological Medicine, vol. 38, no. 11, pp. 1595-1606, 2008.

[101] R. J. Schachar, J. Crosbie, C. L. Barr et al., "Inhibition of motor responses in siblings concordant and discordant for attention deficit hyperactivity disorder," The American Journal of Psychiatry, vol. 162, no. 6, pp. 1076-1082, 2005.

[102] S. S.-F. Gau and C.-Y. Shang, "Executive functions as endophenotypes in ADHD: evidence from the Cambridge Neuropsychological Test Battery (CANTAB)," Journal of Child Psychology and Psychiatry, vol. 51, no. 7, pp. 838-849, 2010.

[103] H. Uebel, B. Albrecht, P. Asherson et al., "Performance variability, impulsivity errors and the impact of incentives as genderindependent endophenotypes for ADHD," Journal of Child Psychology and Psychiatry, vol. 51, no. 2, pp. 210-218, 2010.

[104] R. Marco, A. Miranda, W. Schlotz et al., "Delay and reward choice in ADHD: an experimental test of the role of delay aversion," Neuropsychology, vol. 23, no. 3, pp. 367-380, 2009.

[105] B. Albrecht, D. Brandeis, H. Uebel et al., "Action monitoring in boys with attention-deficit/hyperactivity disorder, their nonaffected siblings, and normal control subjects: evidence for an endophenotype," Biological Psychiatry, vol. 64, no. 7, pp. 615$625,2008$.

[106] H. van Ewijk, D. J. Heslenfeld, M. Luman et al., "Visuospatial working memory in ADHD patients, unaffected siblings, and healthy controls," Journal of Attention Disorders, vol. 18, no. 4, pp. 369-378, 2014.

[107] A. J. A. M. Thissen, N. N. J. Rommelse, P. J. Hoekstra et al., "Attention deficit hyperactivity disorder (ADHD) and executive functioning in affected and unaffected adolescents and their parents: challenging the endophenotype construct," Psychological Medicine, vol. 44, no. 4, pp. 881-892, 2014. 
[108] S. Durston, H. E. Hulshoff Pol, H. G. Schnack et al., "Magnetic resonance imaging of boys with attention-deficit/hyperactivity disorder and their unaffected siblings," Journal of the American Academy of Child and Adolescent Psychiatry, vol. 43, no. 3, pp. 332-340, 2004.

[109] S. Durston, J. A. Fossella, M. J. Mulder et al., "Dopamine transporter genotype conveys familial risk of attention-deficit/ hyperactivity disorder through striatal activation," Journal of the American Academy of Child and Adolescent Psychiatry, vol. 47, no. 1, pp. 61-67, 2008.

[110] E. J. S. Sonuga-Barke, M. Thompson, J. Stevenson, and D. Viney, "Patterns of behaviour problems among pre-school children," Psychological Medicine, vol. 27, no. 4, pp. 909-918, 1997.

[111] K. G. Smith and P. Corkum, "Systematic review of measures used to diagnose attention-deficit/ hyperactivity disorder in research on preschool children," Topics in Early Childhood Special Education, vol. 27, no. 3, pp. 164-173, 2007.

[112] E. J. Sonuga-Barke, J. Koerting, E. Smith, D. C. McCann, and M. Thompson, "Early detection and intervention for attentiondeficit/hyperactivity disorder," Expert Review of Neurotherapeutics, vol. 11, no. 4, pp. 557-563, 2011.

[113] G. Esser, S. Fischer, A. Wyschkon, M. Laucht, and M. H. Schmidt, "Predictors of hyperkinetic disorder-early recognition in childhood," Zeitschrift für Kinder- und Jugendpsychiatrie und Psychotherapie, vol. 35, no. 2, pp. 127-136, 2007.

[114] J. M. Jester, J. T. Nigg, K. Adams et al., "Inattention/hyperactivity and aggression from early childhood to adolescence: heterogeneity of trajectories and differential influence of family environment characteristics," Development and Psychopathology, vol. 17, no. 1, pp. 99-125, 2005.

[115] D. Cicchetti and J. A. Blender, "A multiple-levels-of-analysis perspective on resilience: implications for the developing brain, neural plasticity, and preventive interventions," Annals of the New York Academy of Sciences, vol. 1094, no. 1, pp. 248-258, 2006.

[116] E. J. S. Sonuga-Barke and J. M. Halperin, "Developmental phenotypes and causal pathways in attention deficit/hyperactivity disorder: potential targets for early intervention?" Journal of Child Psychology and Psychiatry, vol. 51, no. 4, pp. 368-389, 2010.

[117] N. N. J. Rommelse, B. Franke, H. M. Geurts, C. A. Hartman, and J. K. Buitelaar, "Shared heritability of attentiondeficit/hyperactivity disorder and autism spectrum disorder," European Child \& Adolescent Psychiatry, vol. 19, no. 3, pp. 281295, 2010.

[118] B. S. Pourcain, W. P. Mandy, J. Heron, J. Golding, G. D. Smith, and D. H. Skuse, "Links between co-occurring socialcommunication and hyperactive-inattentive trait trajectories," Journal of the American Academy of Child \& Adolescent Psychiatry, vol. 50, no. 9, pp. 892.e5-902.e5, 2011.

[119] M. Cooper, J. Martin, K. Langley, M. Hamshere, and A. Thapar, "Autistic traits in children with ADHD index clinical and cognitive problems," European Child \& Adolescent Psychiatry, vol. 23, no. 1, pp. 23-34, 2014.

[120] A. M. Reiersen, J. N. Constantino, H. E. Volk, and R. D. Todd, "Autistic traits in a population-based ADHD twin sample," Journal of Child Psychology and Psychiatry and Allied Disciplines, vol. 48, no. 5, pp. 464-472, 2007.

[121] A. Ronald, E. Simonoff, J. Kuntsi, P. Asherson, and R. Plomin, "Evidence for overlapping genetic influences on autistic and ADHD behaviours in a community twin sample," Journal of Child Psychology and Psychiatry and Allied Disciplines, vol. 49, no. 5, pp. 535-542, 2008.
[122] M. J. Taylor, T. Charman, E. B. Robinson et al., "Developmental associations between traits of autism spectrum disorder and attention deficit hyperactivity disorder: a genetically informative, longitudinal twin study," Psychological Medicine, vol. 43, no. 8, pp. 1735-1746, 2013.

[123] M. Gill, R. Anney, and A. Mulligan, "Overlap between ADHD and autism-clinical and genetic evidence," Current Psychiatry Reviews, vol. 10, no. 2, pp. 143-155, 2014.

[124] J. Martin, M. Cooper, M. L. Hamshere et al., "Biological overlap of attention-deficit/hyperactivity disorder and autism spectrum disorder: evidence from copy number variants," Journal of the American Academy of Child \& Adolescent Psychiatry, vol. 53, no. 7, pp. 761.e26-770.e26, 2014.

[125] A. Mulligan, R. J. L. Anney, M. O’Regan et al., “Autism symptoms in attention-deficit/hyperactivity disorder: a familial trait which correlates with conduct, oppositional defiant, language and motor disorders," Journal of Autism and Developmental Disorders, vol. 39, no. 2, pp. 197-209, 2009.

[126] N. N. J. Rommelse, M. E. Altink, E. A. Fliers et al., "Comorbid problems in ADHD: degree of association, shared endophenotypes, and formation of distinct subtypes. Implications for a future DSM," Journal of Abnormal Child Psychology, vol. 37, no. 6, pp. 793-804, 2009.

[127] E. Pettersson, H. Anckarsäter, C. Gillberg, and P. Lichtenstein, "Different neurodevelopmental symptoms have a common genetic etiology," Journal of Child Psychology and Psychiatry, vol. 54, no. 12, pp. 1356-1365, 2013.

[128] H. Tager-Flusberg, "The origins of social impairments in autism spectrum disorder: studies of infants at risk," Neural Networks, vol. 23, no. 8-9, pp. 1072-1076, 2010.

[129] C. P. Johnson, S. M. Myers, P. H. Lipkin et al., "Identification and evaluation of children with autism spectrum disorders," Pediatrics, vol. 120, no. 5, pp. 1183-1215, 2007.

[130] D. S. Mandell, W. W. Thompson, E. S. Weintraub, F. DeStefano, and M. B. Blank, "Trends in diagnosis rates for autism and ADHD at hospital discharge in the context of other psychiatric diagnoses," Psychiatric Services, vol. 56, no. 1, pp. 56-62, 2005.

[131] M. Yeargin-Allsopp, C. Rice, T. Karapurkar, N. Doernberg, C. Boyle, and C. Murphy, "Prevalence of autism in a US metropolitan area," Journal of the American Medical Association, vol. 289, no. 1, pp. 49-55, 2003.

[132] L. Zwaigenbaum, S. Bryson, C. Lord et al., "Clinical assessment and management of toddlers with suspected autism spectrum disorder: insights from studies of high-risk infants," Pediatrics, vol. 123, no. 5, pp. 1383-1391, 2009.

[133] P. A. Filipek, P. J. Accardo, S. Ashwal et al., "Practice parameter: screening and diagnosis of autism. Report of the quality standards subcommittee of the American Academy of Neurology and the Child Neurology Society," Neurology, vol. 55, no. 4, pp. 468-479, 2000.

[134] S. L. Smalley, V. Kustanovich, S. L. Minassian et al., "Genetic linkage of attention-deficit/hyperactivity disorder on chromosome 16p13, in a region implicated in autism," The American Journal of Human Genetics, vol. 71, no. 4, pp. 959-963, 2002.

[135] S. Dosreis, C. L. Weiner, L. Johnson, and C. J. Newschaffer, "Autism spectrum disorder screening and management practices among general pediatric providers," Journal of Developmental \& Behavioral Pediatrics, vol. 27, no. 2, pp. S88-S94, 2006.

[136] S. H. Landry, K. E. Smith, P. R. Swank, M. A. Assel, and S. Vellet, "Does early responsive parenting have a special importance for children's development or is consistency across early childhood 
necessary?” Developmental Psychology, vol. 37, no. 3, pp. 387403, 2001.

[137] M. W. Wan, J. Green, M. Elsabbagh, M. Johnson, T. Charman, and F. Plummer, "Quality of interaction between at-risk infants and caregiver at 12-15 months is associated with 3-year autism outcome," Journal of Child Psychology and Psychiatry, vol. 54, no. 7, pp. 763-771, 2013.

[138] J. Green, M. W. Wan, J. Guiraud et al., "Intervention for infants at risk of developing autism: a case series," Journal of Autism and Developmental Disorders, vol. 43, no. 11, pp. 2502-2514, 2013.

[139] A. M. Steiner, G. W. Gengoux, A. Klin, and K. Chawarska, "Pivotal response treatment for infants at-risk for autism spectrum disorders: a pilot study," Journal of Autism and Developmental Disorders, vol. 43, no. 1, pp. 91-102, 2013.

[140] L. K. Koegel, A. K. Singh, R. L. Koegel, J. R. Hollingsworth, and J. Bradshaw, "Assessing and improving early social engagement in infants," Journal of Positive Behavior Interventions, vol. 16, no. 2, pp. 69-80, 2014.

[141] J. Green, T. Charman, A. Pickles et al., "Parent-mediated intervention versus no intervention for infants at high risk of autism: a parallel, single-blind, randomised trial," The Lancet Psychiatry, vol. 2, no. 2, pp. 133-140, 2015.

[142] F. Juffer, M. J. Bakermans-Kranenburg, and M. H. van Ijzendoorn, Promoting Positive Parenting: An Attachment-Based Intervention, Routledge, 2012.

[143] S. J. Webb, E. J. H. Jones, J. Kelly, and G. Dawson, “The motivation for very early intervention for infants at high risk for autism spectrum disorders," International Journal of SpeechLanguage Pathology, vol. 16, no. 1, pp. 36-42, 2014.

[144] N. Bauminger, "The facilitation of social-emotional understanding and social interaction in high-functioning children with autism: intervention outcomes," Journal of Autism and Developmental Disorders, vol. 32, no. 4, pp. 283-298, 2002.

[145] T. Klingberg, E. Fernell, P. J. Olesen et al., "Computerized training of working memory in children with ADHD—a randomized, controlled trial," Journal of the American Academy of Child \& Adolescent Psychiatry, vol. 44, no. 2, pp. 177-186, 2005.

[146] E. J. S. Sonuga-Barke, M. Thompson, H. Abikoff, R. Klein, and L. M. Brotman, "Nonpharmacological interventions for preschoolers with ADHD: the case for specialized parent training," Infants \& Young Children, vol. 19, no. 2, pp. 142-153, 2006.

[147] M. E. Toplak, L. Connors, J. Shuster, B. Knezevic, and S. Parks, "Review of cognitive, cognitive-behavioral, and neuralbased interventions for Attention-Deficit/Hyperactivity Disorder (ADHD)," Clinical Psychology Review, vol. 28, no. 5, pp. 801$823,2008$.

[148] S. W. White, K. Keonig, and L. Scahill, "Social skills development in children with autism spectrum disorders: a review of the intervention research," Journal of Autism and Developmental Disorders, vol. 37, no. 10, pp. 1858-1868, 2007.

[149] S. R. McConnell, "Interventions to facilitate social interaction for young children with autism: review of available research and recommendations for educational intervention and future research," Journal of Autism and Developmental Disorders, vol. 32, no. 5, pp. 351-372, 2002.

[150] B. L. Goodlin-Jones, F. Tassone, L. W. Gane, and R. J. Hagerman, "Autistic spectrum disorder and the fragile X premutation," Journal of Developmental \& Behavioral Pediatrics, vol. 25, no. 6, pp. 392-398, 2004.

[151] F. Farzin, H. Perry, D. Hessl et al., "Autism spectrum disorders and attention-deficit/hyperactivity disorder in boys with the fragile X premutation," Journal of Developmental \& Behavioral Pediatrics, vol. 27, no. 2, pp. S137-S144, 2006.

[152] J. E. Hunter, M. P. Epstein, S. W. Tinker, A. Abramowitz, and S. L. Sherman, "The FMR1 premutation and attentiondeficit hyperactivity disorder (ADHD): evidence for a complex inheritance," Behavior Genetics, vol. 42, no. 3, pp. 415-422, 2012.

[153] C. M. Kraan, D. R. Hocking, N. Georgiou-Karistianis et al., "Impaired response inhibition is associated with self-reported symptoms of depression, anxiety, and ADHD in female FMR1 premutation carriers," American Journal of Medical Genetics, Part B: Neuropsychiatric Genetics, vol. 165, no. 1, pp. 41-51, 2014.

[154] F. J. Serajee, R. Nabi, H. Zhong, and A. H. Mahbubul Huq, "Association of INPP1, PIK3CG, and TSC2 gene variants with autistic disorder: implications for phosphatidylinositol signalling in autism," Journal of Medical Genetics, vol. 40, no. 11, article el19, 2003.

[155] International Molecular Genetic Study of Autism Consortium (IMGSAC), "A genomewide screen for autism: strong evidence for linkage to chromosomes 2q, 7q, and 16p," The American Journal of Human Genetics, vol. 69, no. 3, pp. 570-581, 2001.

[156] P. Lucarelli, S. Palminiello, P. Saccucci et al., "Association study of autistic disorder and chromosome 16p," American Journal of Medical Genetics Part A, vol. 119, no. 2, pp. 242-246, 2003.

[157] E. D’Agati, R. Moavero, C. Cerminara, and P. Curatolo, "Attention-deficit hyperactivity disorder (ADHD) and tuberous sclerosis complex," Journal of Child Neurology, vol. 24, no. 10, pp. 1282-1287, 2009.

[158] M. N. Ogdie, S. E. Fisher, M. Yang et al., "Attention deficit hyperactivity disorder: fine mapping supports linkage to 5p13, 6q12, $16 \mathrm{p} 13$, and 17p11," The American Journal of Human Genetics, vol. 75, no. 4, pp. 661-668, 2004.

[159] T. Marui, O. Hashimoto, E. Nanba et al., "Association between the neurofibromatosis-1 (NF1) locus and autism in the Japanese population," American Journal of Medical GeneticsNeuropsychiatric Genetics, vol. 131, no. 1, pp. 43-47, 2004.

[160] O. Mbarek, S. Marouillat, J. Martineau, C. Barthélémy, J.-P. Müh, and C. Andres, "Association study of the NF1 gene and autistic disorder," American Journal of Medical Genetics, vol. 88, no. 6, pp. 729-732, 1999.

[161] K. Lidzba, S. Granström, J. Lindenau, and V.-F. Mautner, "The adverse influence of attention-deficit disorder with or without hyperactivity on cognition in neurofibromatosis type 1," Developmental Medicine \& Child Neurology, vol. 54, no. 10, pp. 892-897, 2012.

[162] C. M. Durand, C. Betancur, T. M. Boeckers et al., "Mutations in the gene encoding the synaptic scaffolding protein SHANK3 are associated with autism spectrum disorders," Nature Genetics, vol. 39, no. 1, pp. 25-27, 2007.

[163] R. Moessner, C. R. Marshall, J. S. Sutcliffe et al., "Contribution of SHANK3 mutations to autism spectrum disorder," The American Journal of Human Genetics, vol. 81, no. 6, pp. 12891297, 2007.

[164] A. Denayer, H. Van Esch, T. De Ravel et al., "Neuropsychopathology in 7 patients with the 22q13 deletion syndrome: presence of bipolar disorder and progressive loss of skills," Molecular Syndromology, vol. 3, no. 1, pp. 14-20, 2012.

[165] G. Barnby, A. Abbott, N. Sykes et al., "Candidate-gene screening and association analysis at the autism-susceptibility locus on chromosome 16p: evidence of association at GRIN2A and ABAT," The American Journal of Human Genetics, vol. 76, no. 6, pp. 950-966, 2005. 
[166] S. E. Fisher, C. Francks, J. T. McCracken et al., "A genomewide scan for loci involved in attention-deficit/hyperactivity disorder," The American Journal of Human Genetics, vol. 70, no. 5, pp. 1183-1196, 2002.

[167] D. Q. Ma, P. L. Whitehead, M. M. Menold et al., "Identification of significant association and gene-gene interaction of GABA receptor subunit genes in autism," The American Journal of Human Genetics, vol. 77, no. 3, pp. 377-388, 2005.

[168] A. L. Collins, D. Ma, P. L. Whitehead et al., "Investigation of autism and GABA receptor subunit genes in multiple ethnic groups," Neurogenetics, vol. 7, no. 3, pp. 167-174, 2006.

[169] P. Purkayastha, A. Malapati, P. Yogeeswari, and D. Sriram, "A review on GABA/glutamate pathway for therapeutic intervention of ASD and ADHD," Current Medicinal Chemistry, vol. 22, no. 15, pp. 1850-1859, 2015.

[170] S. Nagamitsu, Y. Yamashita, H. Tanigawa et al., "Upregulated GABA inhibitory function in $\mathrm{AD} / \mathrm{HD}$ children with child behavior checklist-dysregulation profile: 123I-iomazenil SPECT study," Frontiers in Psychiatry, vol. 6, article 84, 2015.

[171] J. S. Sutcliffe, R. J. Delahanty, H. C. Prasad et al., "Allelic heterogeneity at the serotonin transporter locus (SLC6A4) confers susceptibility to autism and rigid-compulsive behaviors," The American Journal of Human Genetics, vol. 77, no. 2, pp. 265-279, 2005.

[172] A. M. Coutinho, I. Sousa, M. Martins et al., "Evidence for epistasis between SLC6A4 and ITGB3 in autism etiology and in the determination of platelet serotonin levels," Human Genetics, vol. 121, no. 2, pp. 243-256, 2007.

[173] L. Kent, U. Doerry, E. Hardy et al., "Evidence that variation at the serotonin transporter gene influences susceptibility to attention deficit hyperactivity disorder (ADHD): analysis and pooled analysis," Molecular Psychiatry, vol. 7, no. 8, pp. 908-912, 2002.

[174] S. Curran, S. Purcell, I. Craig, P. Asherson, and P. Sham, "The serotonin transporter gene as a QTL for ADHB," American Journal of Medical Genetics B: Neuropsychiatric Genetics, vol. 134, no. 1, pp. 42-47, 2005.

[175] K. D. Gadow, J. Roohi, C. J. DeVincent, and E. Hatchwell, "Association of ADHD, tics, and anxiety with dopamine transporter (DAT1) genotype in autism spectrum disorder," The Journal of Child Psychology and Psychiatry, vol. 49, no. 12, pp. 1331-1338, 2008.

[176] E. Bowton, C. Saunders, I. A. Reddy et al., "SLC6A3 coding variant Ala559Val found in two autism probands alters dopamine transporter function and trafficking," Translational Psychiatry, vol. 4, no. 10, article e464, 2014.

[177] E. H. Cook Jr., M. A. Stein, M. D. Krasowski et al., "Association of attention-deficit disorder and the dopamine transporter gene," The American Journal of Human Genetics, vol. 56, no. 4, pp. 993-998, 1995.

[178] I. R. Gizer, C. Ficks, and I. D. Waldman, "Candidate gene studies of ADHD: a meta-analytic review," Human Genetics, vol. 126, no. 1, pp. 51-90, 2009.

[179] S. Jacob, C. W. Brune, C. S. Carter, B. L. Leventhal, C. Lord, and E. H. Cook Jr., "Association of the oxytocin receptor gene (OXTR) in Caucasian children and adolescents with autism," Neuroscience Letters, vol. 417, no. 1, pp. 6-9, 2007.

[180] S. Wu, M. Jia, Y. Ruan et al., "Positive association of the oxytocin receptor gene (OXTR) with autism in the Chinese Han population," Biological Psychiatry, vol. 58, no. 1, pp. 74-77, 2005.

[181] J. Park, M. Willmott, G. Vetuz et al., "Evidence that genetic variation in the oxytocin receptor (OXTR) gene influences social cognition in ADHD," Progress in Neuro-Psychopharmacology and Biological Psychiatry, vol. 34, no. 4, pp. 697-702, 2010.

[182] N. Yirmiya, C. Rosenberg, S. Levi et al., "Association between the arginine vasopressin la receptor (AVPRla) gene and autism in a family-based study: mediation by socialization skills," Molecular Psychiatry, vol. 11, no. 5, pp. 488-494, 2006.

[183] S. Y. Yang, S.-C. Cho, H. J. Yoo et al., "Association study between single nucleotide polymorphisms in promoter region of AVPR1A and Korean autism spectrum disorders," Neuroscience Letters, vol. 479, no. 3, pp. 197-200, 2010.

[184] M. Wade, T. J. Hoffmann, and J. M. Jenkins, "Association between the arginine vasopressin receptor 1A (AVPR1A) gene and preschoolers' executive functioning," Brain and Cognition, vol. 90, pp. 116-123, 2014.

[185] D. Braida, F. R. Guerini, L. Ponzoni et al., "Association between SNAP-25 gene polymorphisms and cognition in autism: functional consequences and potential therapeutic strategies," Translational Psychiatry, vol. 5, no. 1, article e500, 2015.

[186] F. R. Guerini, E. Bolognesi, M. Chiappedi et al., "SNAP-25 single nucleotide polymorphisms are associated with hyperactivity in autism spectrum disorders," Pharmacological Research, vol. 64, no. 3, pp. 283-288, 2011.

[187] K. Brophy, Z. Hawi, A. Kirley, M. Fitzgerald, and M. Gill, "Synaptosomal-associated protein 25 (SNAP-25) and attention deficit hyperactivity disorder (ADHD): evidence of linkage and association in the Irish population," Molecular Psychiatry, vol. 7, no. 8, pp. 913-917, 2002.

[188] K. C. Kondapalli, A. Hack, M. Schushan, M. Landau, N. BenTal, and R. Rao, "Functional evaluation of autism-associated mutations in NHE9," Nature Communications, vol. 4, article 2510, 2013.

[189] M. Wagle and J. Holder, "Exonic deletion of $\mathrm{SLC}_{9} \mathrm{~A}_{9}$ in autism with epilepsy $\left(\mathrm{P}_{4.33} 8\right)$," Neurology, vol. 82 , no. 10, supplement, p. P4.338, 2014.

[190] M. G. De Silva, K. Elliott, H.-H. Dahl et al., "Disruption of a novel member of a sodium/hydrogen exchanger family and DOCK3 is associated with an attention deficit hyperactivity disorder-like phenotype," Journal of Medical Genetics, vol. 40, no. 10, pp. 733-740, 2003.

[191] J. Lasky-Su, B. M. Neale, B. Franke et al., "Genome-wide association scan of quantitative traits for attention deficit hyperactivity disorder identifies novel associations and confirms candidate gene associations," American Journal of Medical Genetics Part B: Neuropsychiatric Genetics, vol. 147, no. 8, pp. 1345-1354, 2008.

[192] E. Mick, A. Todorov, S. Smalley et al., "Family-based genomewide association scan of attention-deficit/hyperactivity disorder," Journal of the American Academy of Child \& Adolescent Psychiatry, vol. 49, no. 9, pp. 898.e3-905.e3, 2010.

[193] G. M. Orabona, K. Griesi-Oliveira, E. Vadasz et al., "HTR1B and HTR2C in autism spectrum disorders in Brazilian families," Brain Research, vol. 1250, pp. 14-19, 2009.

[194] J. W. Smoller, J. Biederman, L. Arbeitman et al., "Association between the $5 \mathrm{HT} 1 \mathrm{~B}$ receptor gene $(H T R 1 B)$ and the inattentive subtype of ADHD," Biological Psychiatry, vol. 59, no. 5, pp. 460467, 2006.

[195] Z. Hawi, M. Dring, A. Kirley et al., "Serotonergic system and attention deficit hyperactivity disorder (ADHD): a potential susceptibility locus at the 5-HT1B receptor gene in 273 nuclear families from a multi-centre sample," Molecular Psychiatry, vol. 7, no. 7, pp. 718-725, 2002. 
[196] S. Jamain, H. Quach, C. Betancur et al., "Mutations of the Xlinked genes encoding neuroligins NLGN3 and NLGN4 are associated with autism," Nature Genetics, vol. 34, no. 1, pp. 2729, 2003.

[197] F. Laumonnier, F. Bonnet-Brilhault, M. Gomot et al., "X-linked mental retardation and autism are associated with a mutation in the NLGN4 gene, a member of the neuroligin family," The American Journal of Human Genetics, vol. 74, no. 3, pp. 552-557, 2004.

[198] F. Lonardo, G. Parenti, D. V. Luquetti et al., "Contiguous gene syndrome due to an interstitial deletion in Xp22.3 in a boy with ichthyosis, chondrodysplasia punctata, mental retardation and ADHD," European Journal of Medical Genetics, vol. 50, no. 4, pp. 301-308, 2007.

[199] A. J. Stam, P. F. Schothorst, J. A. S. Vorstman, and W. G. Staal, "The genetic overlap of attention deficit hyperactivity disorder and autistic spectrum disorder," The Application of Clinical Genetics, vol. 2, pp. 7-13, 2009.

[200] K. D. Gadow, C. J. Devincent, D. M. Olvet, V. Pisarevskaya, and E. Hatchwell, "Association of DRD4 polymorphism with severity of oppositional defiant disorder, separation anxiety disorder and repetitive behaviors in children with autism spectrum disorder," European Journal of Neuroscience, vol. 32, no. 6, pp. 1058-1065, 2010.

[201] K. D. Gadow, C. J. DeVincent, V. Pisarevskaya et al., "Parentchild DRD4 genotype as a potential biomarker for oppositional, anxiety, and repetitive behaviors in children with autism spectrum disorder," Progress in Neuro-Psychopharmacology and Biological Psychiatry, vol. 34, no. 7, pp. 1208-1214, 2010.

[202] S. V. Faraone, A. E. Doyle, E. Mick, and J. Biederman, "Metaanalysis of the association between the 7-repeat allele of the dopamine $\mathrm{D}_{4}$ receptor gene and attention deficit hyperactivity disorder," The American Journal of Psychiatry, vol. 158, no. 7, pp. 1052-1057, 2001.

[203] J. Feng, J. L. Sobell, L. L. Heston, E. H. Cook Jr., D. Goldman, and S. S. Sommer, "Scanning of the dopamine D1 and D5 receptor genes by REF in neuropsychiatric patients reveals a novel missense change at a highly conserved amino acid," American Journal of Medical Genetics, vol. 81, no. 2, pp. 172-178, 1998.

[204] J. Lasky-Su, J. Biederman, N. Laird et al., "Evidence for an association of the dopamine D5 receptor gene on age at onset of attention deficit hyperactivity disorder," Annals of Human Genetics, vol. 71, no. 5, pp. 648-659, 2007.

[205] M. de Krom, W. G. Staal, R. A. Ophoff et al., "A common variant in DRD3 receptor is associated with autism spectrum disorder," Biological Psychiatry, vol. 65, no. 7, pp. 625-630, 2009.

[206] W. G. Staal, M. de Krom, and M. V. de Jonge, "Brief report: the dopamine-3-receptor gene ( $D R D 3)$ is associated with specific repetitive behavior in autism spectrum disorder (ASD)," Journal of Autism and Developmental Disorders, vol. 42, no. 5, pp. 885888, 2012.

[207] W. Retz, M. Rösler, T. Supprian, P. Retz-Junginger, and J. Thome, "Dopamine $\mathrm{D}_{3}$ receptor gene polymorphism and violent behavior: relation to impulsiveness and ADHD-related psychopathology," Journal of Neural Transmission, vol. 110, no. 5, pp. 561-572, 2003.

[208] L. K. Davis, H. C. Hazlett, A. L. Librant et al., "Cortical enlargement in autism is associated with a functional VNTR in the monoamine oxidase a gene," American Journal of Medical Genetics, Part B: Neuropsychiatric Genetics, vol. 147, no. 7, pp. 1145-1151, 2008.
[209] I. L. Cohen, X. Liu, C. Schutz et al., "Association of autism severity with a monoamine oxidase A functional polymorphism," Clinical Genetics, vol. 64, no. 3, pp. 190-197, 2003.

[210] D. Verma, B. Chakraborti, A. Karmakar et al., "Sexual dimorphic effect in the genetic association of monoamine oxidase A (MAOA) markers with autism spectrum disorder," Progress in Neuro-Psychopharmacology and Biological Psychiatry, vol. 50, pp. 11-20, 2014.

[211] K. Domschke, K. Sheehan, N. Lowe et al., "Association analysis of the monoamine oxidase A and B genes with attention deficit hyperactivity disorder (ADHD) in an Irish sample: preferential transmission of the MAO-A 941G allele to affected children," American Journal of Medical Genetics: Neuropsychiatric Genetics, vol. 134, no. 1, pp. 110-114, 2005.

[212] I. Manor, S. Tyano, E. Mel et al., "Family-based and association studies of monoamine oxidase A and attention deficit hyperactivity disorder (ADHD): preferential transmission of the long promoter-region repeat and its association with impaired performance on a continuous performance test (TOVA)," Molecular Psychiatry, vol. 7, no. 6, pp. 626-632, 2002.

[213] H. J. Yoo, H. Cho, M. Park, S. Y. Yang, and S. A. Kim, "Association of the catechol-o-methyltransferase gene polymorphisms with korean autism spectrum disorders," Journal of Korean Medical Science, vol. 28, no. 9, pp. 1403-1406, 2013.

[214] T. Guo, W. Wang, B. Liu, H. Chen, and C. Yang, "Catechol-Omethyltransferase Val158Met polymorphism and risk of autism spectrum disorders," Journal of International Medical Research, vol. 41, no. 3, pp. 725-734, 2013.

[215] J. Eisenberg, G. Mei-Tal, A. Steinberg et al., "Haplotype relative risk study of catechol-O-methyltransferase (COMT) and attention deficit hyperactivity disorder (ADHD): association of the high-enzyme activity val allele with ADHD impulsivehyperactive phenotype," American Journal of Medical Genetics, vol. 88, no. 5, pp. 497-502, 1999.

[216] J. Biederman, J. W. Kim, A. E. Doyle et al., "Sexually dimorphic effects of four genes (COMT, SLC6A2, MAOA, SLC6A4) in genetic associations of ADHD: a preliminary study," American Journal of Medical Genetics Part B: Neuropsychiatric Genetics, vol. 147, no. 8, pp. 1511-1518, 2008. 


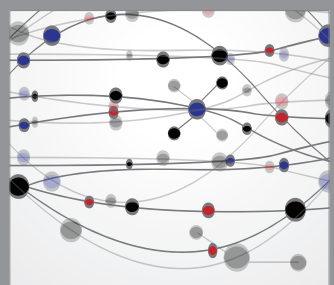

The Scientific World Journal
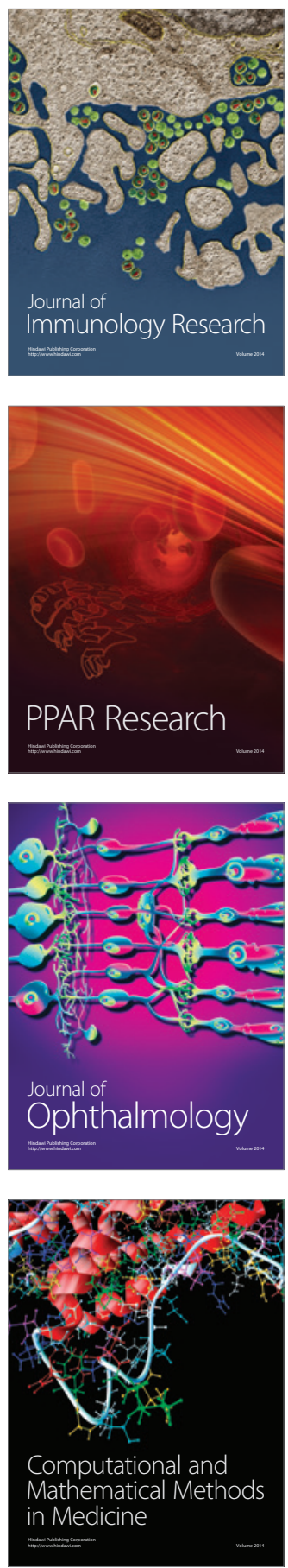

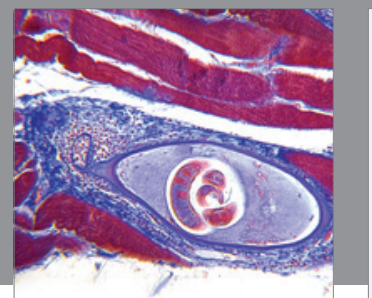

Gastroenterology

Research and Practice
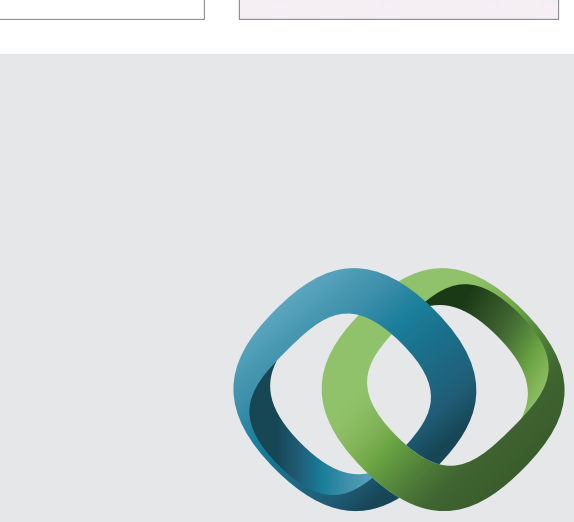

\section{Hindawi}

Submit your manuscripts at

http://www.hindawi.com
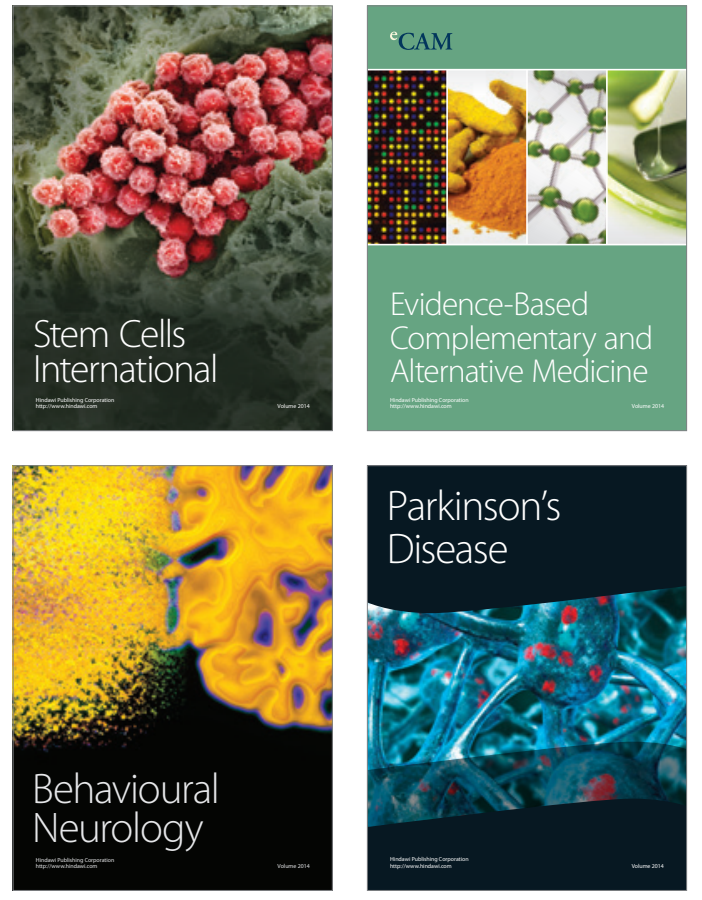
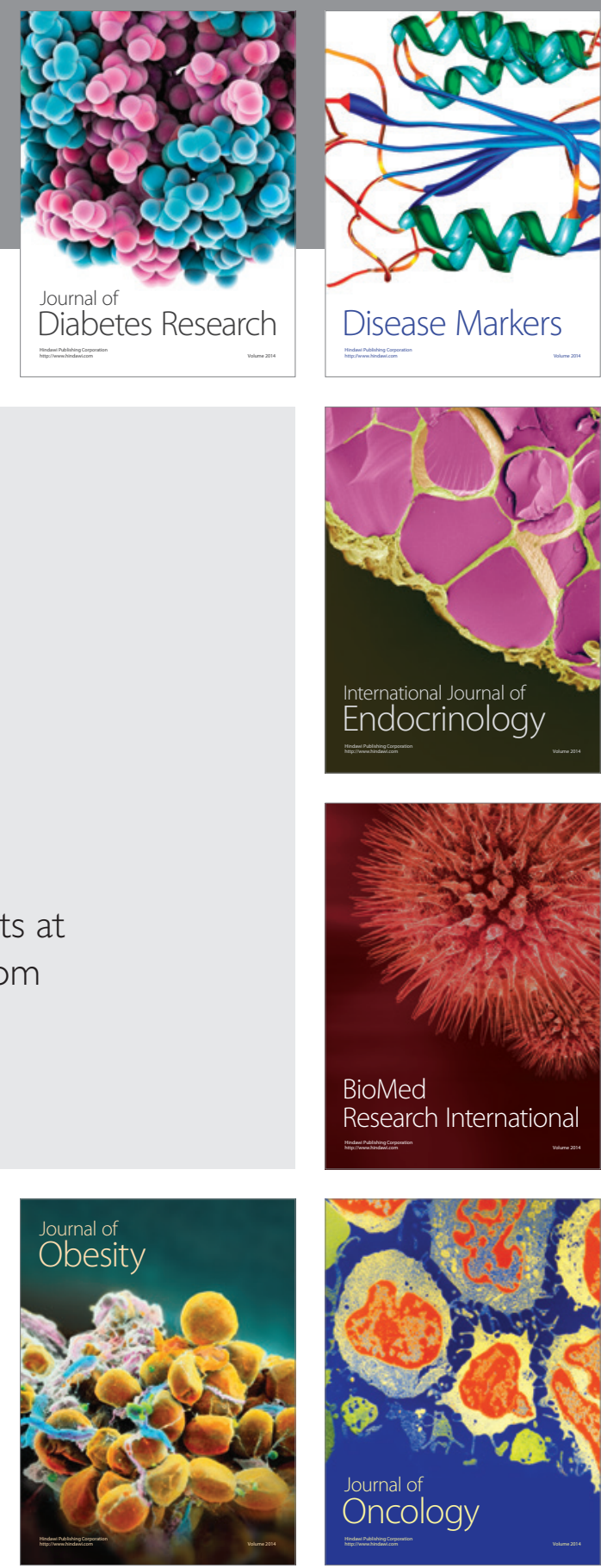

Disease Markers
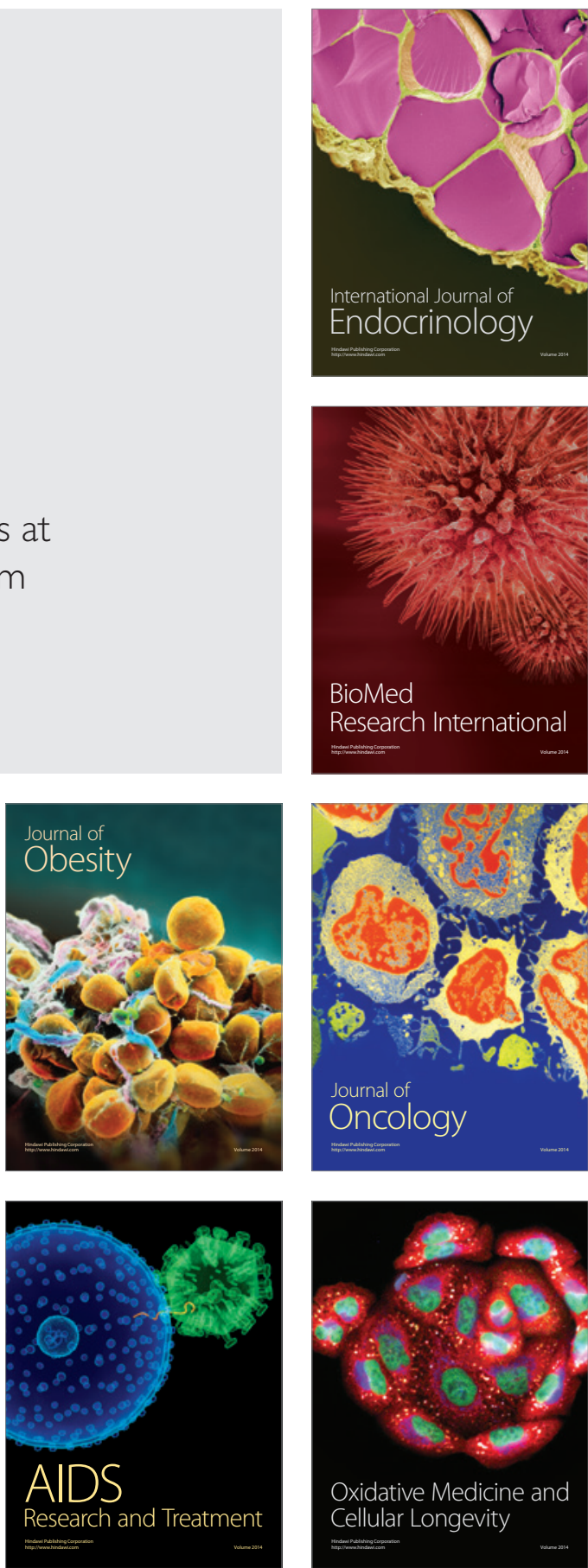